\title{
Modelling the Mediterranean marine ecosystem as a whole: addressing the challenge of complexity
}

\author{
Chiara Piroddii, ${ }^{1, *}$, Marta Coll ${ }^{2,3,4}$, Jeroen Steenbeek ${ }^{4}$, Diego Macias Moy ${ }^{1}$, \\ Villy Christensen ${ }^{4,5}$
}

\author{
${ }^{1}$ European Commission, Joint Research Centre, Institute for Environment and Sustainability, Via Fermi 2749, 21027 Ispra, Italy \\ ${ }^{2}$ Institute of Marine Science (ICM-CSIC), Barcelona, Spain \\ ${ }^{3}$ Institut de Recherche pour le Développement, UMR MARBEC (MARine Biodiverity Exploitation \& Conservation), \\ Avenue Jean Monnet, BP 171, 34203 Sète Cedex, France \\ ${ }^{4}$ Ecopath International Initiative Research Association, Barcelona, Spain \\ ${ }^{5}$ Institute for the Oceans and Fisheries, University of British Columbia, 2202 Main Mall, Vancouver BC V6T 1Z4, Canada
}

\begin{abstract}
An ecosystem modelling approach was used to understand and assess the Mediterranean marine ecosystem structure and function as a whole. In particular, 2 food web models for the 1950s and 2000s were built to investigate: (1) the main structural and functional characteristics of the Mediterranean food web during these 2 time periods; (2) the key species/functional groups and interactions; (3) the role of fisheries and their impact; and (4) the ecosystem properties of the Mediterranean Sea in comparison with other European regional seas. Our results show that small pelagic fishes, mainly European pilchards and anchovies, prevailed in terms of biomasses and catches during both periods. Large pelagic fishes, sharks and medium pelagic fishes played a key role in the 1950s ecosystem, and have been replaced in more recent years by benthopelagic and benthic cephalopods. Fisheries showed large effects on most living groups of the ecosystem in both time periods. When comparing the Mediterranean results to those of other European regional seas modelling initiatives, the Mediterranean stood alone in relation to the type of flows (e.g. Mediterranean Sea, flow to detritus: $42 \%$; other EU seas, consumption: 43-48\%) driving the system and the cycling indices. This suggested higher levels of community stress induced by intensive fishing activities in the Mediterranean basin. This study constitutes the first attempt to build an historical and current food web model for the whole Mediterranean Sea.
\end{abstract}

KEY WORDS: Ecopath model - Food web - Ecosystem modelling • Network analysis · Fishing impact $\cdot$ Mediterranean Sea

\section{INTRODUCTION}

Marine ecosystem models have been progressively employed worldwide to investigate the structure and functioning of marine systems and the effects of anthropogenic pressures such as fishing, climate change and pollution on marine ecosystems (Christensen \& Walters 2004, Shin et al. 2004, Fulton 2010). Understanding the mechanisms behind diverse ecological networks (e.g. trophic interactions and flows) and the roles of human activities on marine structure

*Corresponding author: cpiroddi@hotmail.com and function is critical when managing marine resources (Cury et al. 2003). The development of ecosystem models to explore ecosystem functions and responses to anthropogenic and/or environmental changes has been driven by the so called 'ecosystembased management' (EBM) approach, which aims at managing the whole ecosystem rather than focusing on a single resource, helping researchers and policy makers to answer questions for responsible resource management decisions (Pikitch et al. 2004). Currently, among the most used ecological modelling

๑ The authors 2015. Open Access under Creative Commons by Attribution Licence. Use, distribution and reproduction are unrestricted. Authors and original publication must be credited. 
tools for EBM in the aquatic environment is the software package 'Ecopath with Ecosim' (EwE, Christensen \& Walters 2004; www.ecopath.org). EwE models have been widely used to describe the structure and functioning of marine ecosystems, evaluate the effects of anthropogenic activities and environmental changes and explore fishing management policy options (Coll et al. 2009a, Piroddi et al. 2011, Heymans et al. 2012). Here we applied the EwE approach to describe and assess the Mediterranean marine ecosystem structure and functioning as a whole.

The Mediterranean Sea is a semi-enclosed basin with unique characteristics: it is oligotrophic (Barale \& Gade 2008), highly diverse in species richness (Coll et al. 2010) and yet is considered a sea 'under siege' due to multiple uses and stressors (Coll et al. 2012). Twenty-one countries in Europe, Asia and Africa surround and share this enclosed sea. Their different cultural, social and economic characteristics pose significant challenges to sustainable management of Mediterranean marine resources. As a consequence of this complexity and lack of management strategies that take this complexity into account, the Mediterranean ecosystem has degraded, and many marine species are over-exploited or depleted (Papaconstantinou \& Farrugio 2000, Lleonart \& Maynou 2003, Colloca et al. 2013, Tsikliras et al. 2013b, Vasilakopoulos et al. 2014). Thus, there has been an urgent need to employ EBM as a complementary management framework to address current and future threats to the Mediterranean marine ecosystems.

Several research activities have already been conducted in the region to address this issue at the basin scale. In particular, Coll et al. (2012) and Micheli et al. (2013) investigated the cumulative impacts of specific anthropogenic threats to Mediterranean marine biodiversity. Here, we applied a different approach, that is, the description of the structure and functioning of the whole Mediterranean ecosystem in terms of trophic linkages, trophic flows and biomasses, and between 2 post-World War II decades. Compared to Coll et al. (2012) and Micheli et al. (2013), who used spatial analysis and expert knowledge to assess the impacts on the ecosystem, our study quantifies the trophic interactions and effects of pressures (e.g. in this case fishing) occurring in the whole area, using the best available data to date. A recent study by Coll \& Libralato (2012) highlighted that more than 40 EwE models describing local or regional Mediterranean ecosystems exist (including lagoons, marine reserves and coastal and shelf areas), but none of these past efforts focussed on the Mediterranean Sea as a whole. This is likely due to the complexity of building such an ecosystem model while being able to capture the differences in environmental and biological characteristics of the Mediterranean region, and due to difficulties regarding data mining and integration. Therefore, our study is the first attempt to comprehensively model the Mediterranean basin. Studies like this one become critically important in support of policies like the Marine Strategy Framework Directive (MSFD; 2008/56/EC), the main European Directive on marine waters that requires the assessment of all European seas at regional scales in relation to their ecosystem status and associated pressures, and the establishment of environmental targets (through the use of indicators) to achieve 'Good Environmental Status' by 2020 (Cardoso et al. 2010).

Specifically, in this study we investigated (1) the main structural and functional characteristics of the Mediterranean food web during 2 different time periods, i.e. the 1950s and 2000s; (2) the key species/ functional groups and interactions for both time periods; (3) the role of fisheries and their effects; and (4) the ecosystem properties of the Mediterranean Sea in comparison with other European regional seas, namely the North Sea, Baltic Sea and Black Sea, which have already been modelled at the regional basin scale (Tomczak et al. 2012, 2013, Akoglu et al. 2014, Mackinson 2014).

\section{MATERIALS AND METHODS}

\section{Mediterranean Sea}

The Mediterranean Sea extends from $30^{\circ}$ to $45^{\circ} \mathrm{N}$ and from $6^{\circ} \mathrm{W}$ to $36^{\circ} \mathrm{E}$, and constitutes the world's largest $\left(2522000 \mathrm{~km}^{2}\right.$ ) and deepest (average $1460 \mathrm{~m}$, maximum $5267 \mathrm{~m}$ ) enclosed sea. It is connected to the Atlantic Ocean via the Strait of Gibraltar in the west, to the Black Sea via the Bosporus and the Dardanelles in the north-east, and to the Red Sea via the Suez Canal in the south-east (Fig. 1). Overall, the basin is considered oligotrophic with some exceptions along coastal areas due mainly to river discharges (Barale \& Gade 2008) and frontal mesoscale activity (Siokou-Frangou et al. 2010). Phosphorus, rather than nitrogen, is the limiting nutrient, especially towards the eastern basin (Krom et al. 1991). Biological productivity decreases from north to south and west to east, whereas an opposite trend is observed for temperature and salinity. In particular, the mean sea surface temperature varies between a minimum of $14-16^{\circ} \mathrm{C}$ (west to east) in winter and a max- 


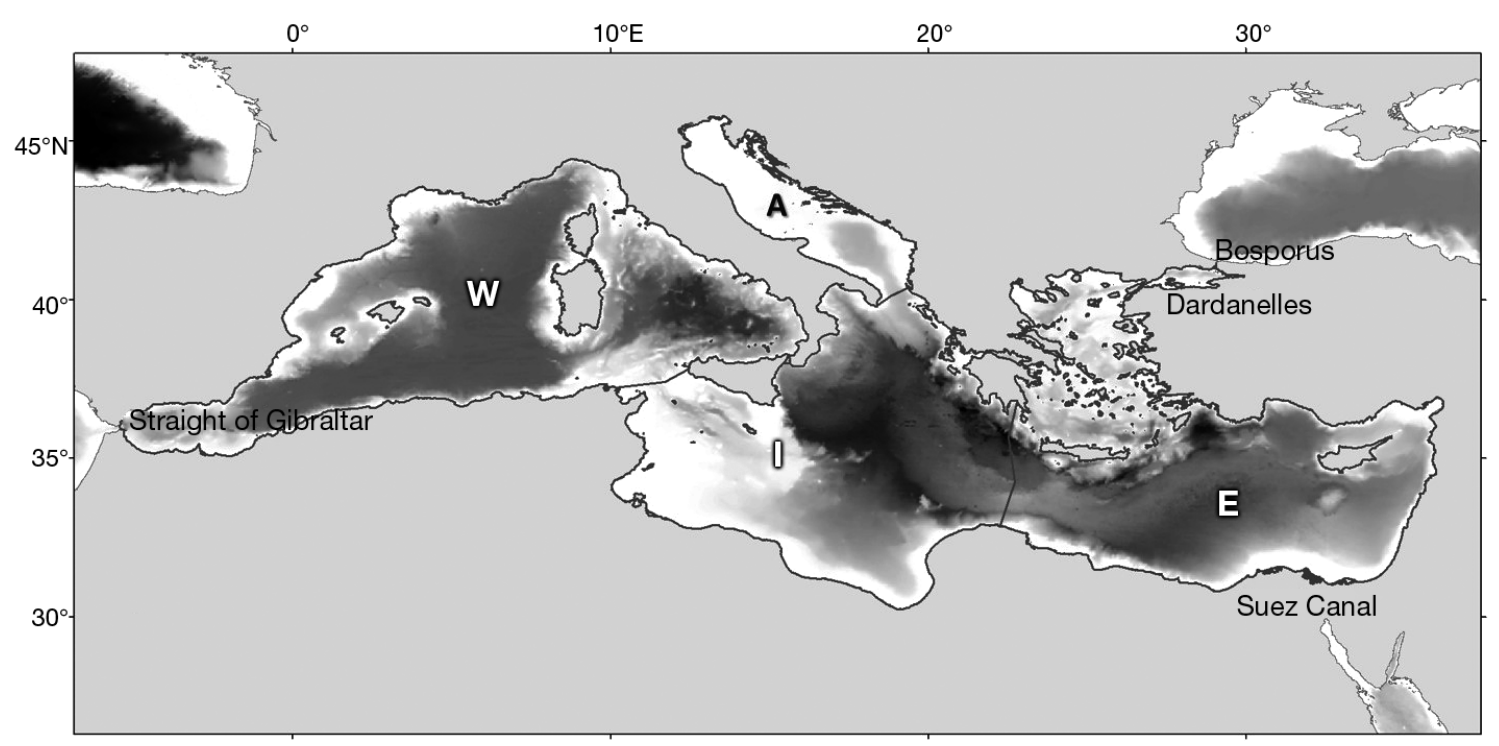

Fig. 1. Mediterranean Sea, showing depth profile (darker shading indicates greater depth) and the 4 Marine Strategy Framework Directive (MSFD) areas: Western Mediterranean Sea (W); Adriatic Sea (A); Ionian and Central Mediterranean Sea (I); Aegean and Levantine Sea (E)

imum of ca. $20-26^{\circ} \mathrm{C}$ (west to east) in the summer (with the exception of the shallow Adriatic Sea, where the range is between $8-10^{\circ} \mathrm{C}$ in winter and $26-28^{\circ} \mathrm{C}$ in summer) (Barale \& Gade 2008). Evaporation greatly exceeds precipitation, and river runoff decreases from west to east, causing sea surface height to decrease and salinity to increase eastward (Coll et al. 2010). The Mediterranean Sea has a topographically diverse continental shelf that generally varies from south (mainly narrow and steep) to north (wider areas). In some instances, however, narrow shelves can also be found on some coasts of Turkey, in the Aegean, Ligurian and northern Alboran Seas, while extended shelves are also present on the Tunisian shelf and near the Nile Delta (Pinardi et al. 2006). Shelf waters represent $20 \%$ of the total Mediterranean surface, and the rest is open sea (Coll et al. 2010).

Mediterranean marine species richness is relatively high; to date, approximately 17000 species have been recorded in the Mediterranean Sea, with a gradient of species richness that decreases from northwest to southeast (Bianchi \& Morri 2000, Coll et al. 2010, 2012). Of these 17000 species, at least $26 \%$ are prokaryotic (Bacteria and Archaea) and eukaryotic (protists) marine microbes. The phytoplankton community is composed predominantly of coccolithophores, dinoflagellates and Bacillariophyceae and includes more than 1500 species. Among microzooplankton, foraminiferans comprise the main group, with more than 600 species. However, the majority of species are described within the Animalia ( 11500 species), with the greatest contribution coming from the Crustacea (13.2\%) and Mollusca (12.4\%) (Coll et al. 2010). Among the vertebrates, 650 species of marine fishes have been recorded, of which approximately 80 are elasmobranchs and the rest are mainly actinopterygians (86\%) (Coll et al. 2010). Nine species of marine mammals (5 Delphinidae, 1 Ziphiidae, 1 Physeteridae, 1 Balaenopteridae and 1 Phocidae) and 3 species of sea turtles (the green turtle Chelonia mydas, the loggerhead Caretta caretta and the leatherback Dermochelys coriacea) are encountered regularly in the Mediterranean Sea. Among seabirds, 15 species frequently occur in the Mediterranean Sea, including 10 gulls and terns (Charadriiformes), 4 shearwaters and storm petrels (Procellariiformes) and 1 shag (Pelecaniformes) (Coll et al. 2010).

\section{Ecosystem modelling approach}

Two food web models of the entire Mediterranean Sea were constructed using the EwE software version 6 (Christensen et al. 2008) representing annual average biomasses and trophic flows for the 1950s and the 2000s. The analysis was restricted to Ecopath, the static component of the software that describes the ecosystem and its resources at a precise period in time (Christensen \& Walters 2004). In Ecopath, all principal autotroph and heterotroph species can be represented either individually or aggregated into functional groups considering their ecological roles. 
The EwE model is based on 2 main equations. In the first one, the biological production of a functional group is equal to the sum of fishing mortality, predation mortality, net migration, biomass accumulation and other unexplained mortality as follows:

$$
\begin{aligned}
& (P / B)_{i} \times B_{i}= \\
& Y_{i}+\sum_{j} B_{j} \times(Q / B)_{j} \times D C_{j i}+E_{i}+B A_{i}+(P / B)_{i} \times B_{i}\left(1-E E_{i}\right)
\end{aligned}
$$

where $P / B$ is the production to biomass ratio for a certain functional group $i, B_{i}$ is the biomass of a group $i$, $Y_{i}$ is the total fishery catch rate of group $i_{r}(Q / B)_{j}$ is the consumption to biomass ratio for each predator $j, D C_{j i}$ is the proportion of group $i$ in the diet of predator $j_{1} E_{i}$ is the net migration rate (emigration - immigration), $B A_{i}$ is the biomass accumulation rate for the group $i$, $E E_{i}$ is the ecotrophic efficiency, and $\left(1-E E_{i}\right)$ represents mortality other than predation and fishing.

In the second equation, the consumption $(Q)$ of a functional group (i) is equal to the sum of production $(P)$, respiration $(R)$ and unassimilated food $(G S \times Q)$.

$$
Q_{i}=P_{i}+R_{i}+G S_{i} \times Q_{i}
$$

The implication of these 2 equations is that the model is mass balanced; under this assumption, Ecopath uses and solves a system of linear equations (1 for each functional group present in the system) estimating the missing parameters.

To ensure the mass balance, we applied a manual mass-balanced procedure following a top-down approach, adjusting the input parameters of those groups 'out of balance' (EE $>1)$, occurring when total energy demand placed on those groups either by predation or fishing exceeds total production. In particular, we changed those parameters associated with higher uncertainty, i.e. diet matrix, $P / B$ and, to a lesser extent, biomass (Christensen \& Walters 2004). The ecological models were considered balanced when (1) estimated $E E$ values were $<1$; (2) gross food conversion efficiency $(P / Q)$ was $<0.5$; and (3) respiration over assimilation $(R / A)$ was $<1$ (Christensen \& Walters 2004).

\section{Parameterization and functional groups}

Two food web models were constructed for the decades of 1950 and 2000, respectively. The reason for choosing these 2 time periods was related to best data collection in the case of the last decade and available catch time series (starting in the 1950s) and biogeochemical/stock assessment model outputs (e.g. biomasses for phytoplankton and fish stocks) for the first decade. To best represent the entire Medi- terranean Sea ecosystem, while still considering sub-regional differences in environmental and biological characteristics, both models were divided in 4 sub-models following the 4 sub-regional divisions defined by the Marine Strategy Framework Directive (MSFD; 2008/56/EC): (1) Western Mediterranean Sea (W); (2) Adriatic Sea (A); (3) Ionian and Central Mediterranean Sea (I); (4) Aegean and Levantine Sea (E) (Fig. 1). To separate each MSFD area within the full single Mediterranean model, we assigned a habitat area which corresponds to the fraction of the total area where the functional groups occur. In particular, if a functional group occurs throughout the total Mediterranean Sea, the biomass is scaled by a factor of 1 ; otherwise biomass is scaled by the fraction of the Mediterranean Sea area occupied (see Tables S1 \& S2 in the Supplement at www.int-res.com/articles/ suppl/m533p047_supp.pdf).

To define functional groups, we used all available data to parameterize the model and ecological traits of species to establish the groups (see Tables S1-S4 in the Supplement).

We divided marine mammals into 'piscivorous cetaceans' (mainly dolphins), 'other cetaceans' (mainly whales) and 'pinnipeds' (monk seal Monachus monachus).

Fishes were divided into 'sharks', 'rays and skates', 'deep-sea fishes' (mainly mesopelagic, bathypelagic and bathydemersal), pelagic fishes and demersal fishes. Pelagic and demersal fishes were further divided in 'small' (common total length $<30 \mathrm{~cm}$ ), 'medium' (30-89 cm) and 'large' ( $\geq 90 \mathrm{~cm}$ ) following a similar approach used by Christensen et al. (2009), which simplified the definition of the fish groups (e.g. piscivores, benthivores and herbivores) in the model parameterization but still considered fish based on their asymptotic length, feeding habitats and vertical distribution characteristics. Invertebrate species were separated into 'benthopelagic' and 'benthic cephalopods', 'bivalves and gastropods', 'crustaceans', 'jellyfishes', 'benthos' and 'zooplankton'. Primary producers were divided in 'phytoplankton' and 'seagrass'. Each MSFD area had the same functional group categories except for highly migratory species such as the 'other cetaceans' group, the 'large pelagic fishes' (e.g. tuna species and swordfish Xiphias gladius) and the 'sea turtles' that were allowed to move and feed in all 4 areas. 'European hake' Merluccius merluccius, 'European pilchard' Sardina pilchardus and 'European anchovy' Engraulis encrasicolus were considered individually due to their importance as commercial species, and thus individual groups were created to represent these species within the model. A total of 103 
functional groups were described to represent the whole Mediterranean Sea model.

For each group, 5 input parameters were estimated: biomass $(B)$, production rate per unit of biomass $(P / B)$, consumption rate per unit of biomass $(Q / B)$, diet composition $(D C)$ and fisheries catch rate $(Y)$. The biomass of each functional group, expressed as tonnes (t) of wet weight per $\mathrm{km}^{2}$, was obtained from field surveys, estimated from empirical equations of population reconstruction or assessed by biogeochemical models. For the scope of this work, we searched mainly for data available at regional scales (either from survey campaigns or from other model outputs), and when this information was not available, local case studies were used instead (e.g. 'seagrass' biomass; see Tables S1 \& S2 in the Supplement). For the 1950s model, which lacked surveyed data, the biomasses of commercially important groups (functional groups 6 to 21 in Table 1) were estimated from stock assessments (e.g. International Commission for the Conservation of Atlantic Tunas (ICCAT; https://www. iccat.int/en/pubs_CVSP.htm for the large pelagic fishes) or by applying a logistic growth model (Schaefer 1954) as in previous studies (Walters et al. 2008, Piroddi et al. 2010). In particular, this last method, also called surplus production model, expressed as:

$$
N_{t+1}=N_{t}+r N_{t}\left(1-N_{t} / k\right)-C_{t}
$$

allows estimating the size of a given population/stock $(N)$ at certain time $(t)$ knowing the historical catch time series $\left(C_{t}\right)$, the intrinsic rate of population growth $(r$; obtained from Fishbase, Froese \& Pauly $2010)$ and the carrying capacity $(k)$.

'Phytoplankton' biomass was taken from the outputs of a biogeochemical model developed for the entire Mediterranean Sea (Macias et al. 2014), while 'zooplankton' was obtained from a global database available from the National Oceanic and Atmospheric Administration (www.st.nmfs.noaa.gov). For the other functional groups, information was available either through the literature (e.g. 'pinnipeds' and 'sea turtles') or reconstructed from global databases (e.g. seabird biomass from the Sea Around Us Project; www.seaaroundus.org). The $P / B$ and $Q / B$ ratios were estimated using empirical equations (Christensen et al. 2008) or taken from the literature and were expressed as annual rates $\left(\mathrm{t} \mathrm{km}^{-2} \mathrm{yr}^{-1}\right)$ (Tables S1 \& S2 in the Supplement). A diet composition matrix was constructed using either field studies (e.g. stomach contents) or diet data obtained from the literature for the same species in similar ecosystems (Table S3 in the Supplement). For highly migratory species ('large pelagic fishes', 'other cetaceans' and
Table 1. Functional groups and fisheries included in the models together with their abbreviations

\begin{tabular}{|c|c|c|}
\hline No. & Functional groups/fisheries & Abbreviation \\
\hline 1 & Piscivorous cetaceans & PC \\
\hline 2 & Other cetaceans & $\mathrm{OC}$ \\
\hline 3 & Pinnipeds & PI \\
\hline 4 & Seabirds & SB \\
\hline 5 & Sea turtles & $\mathrm{ST}$ \\
\hline 6 & Large pelagic fishes & LP \\
\hline 7 & Medium pelagic fishes & MP \\
\hline 8 & European pilchard & $\mathrm{EP}$ \\
\hline 9 & European anchovy & EA \\
\hline 10 & Other small pelagic fishes & SP \\
\hline 11 & Large demersal fishes & LD \\
\hline 12 & European hake & HK \\
\hline 13 & Medium demersal fishes & MD \\
\hline 14 & Small demersal fishes & $\mathrm{SD}$ \\
\hline 15 & Deep-sea fishes & DF \\
\hline 16 & Sharks & SK \\
\hline 17 & Rays and skates & $\mathrm{RS}$ \\
\hline 18 & Benthopelagic cephalopods & $\mathrm{BPC}$ \\
\hline 19 & Benthic cephalopods & $\mathrm{BC}$ \\
\hline 20 & Bivalves and gastropods & BG \\
\hline 21 & Crustaceans & $\mathrm{CR}$ \\
\hline 22 & Jellyfish & JF \\
\hline 23 & Benthos & $\mathrm{BE}$ \\
\hline 24 & Zooplankton & $\mathrm{ZO}$ \\
\hline 25 & Phytoplankton & $\mathrm{PH}$ \\
\hline 26 & Seagrass & $\mathrm{SE}$ \\
\hline 27 & Discards & DS \\
\hline 28 & Detritus & $\mathrm{DE}$ \\
\hline 29 & Trawlers & $\mathrm{TR}$ \\
\hline 30 & Dredges & DR \\
\hline 31 & Mid-water trawlers & MT \\
\hline 32 & Purse seiners & PS \\
\hline 33 & Long liners & LL \\
\hline 34 & Artisanal fisheries & $\mathrm{AR}$ \\
\hline 35 & Recreational fisheries & $\mathrm{RC}$ \\
\hline
\end{tabular}

'sea turtles') and 'seabirds' groups, we accounted for a percentage of the diet being outside the marine ecosystem, assuming that those species also move outside the studied system for feeding (Coll et al. 2006, 2007, Christensen et al. 2008, Piroddi et al. 2010).

In some instances, we integrated parameters $(B$, $D C, P / B$ and $Q / B$ ) from previously built EwE models for different areas of the Mediterranean Sea (Adriatic Sea: Coll et al. 2007, 2009c; Catalan Sea: Coll et al. 2006, 2008, Tecchio et al. 2013; Ionian Sea: Piroddi et al. 2010, 2011, Moutopoulos et al. 2013; Aegean Sea: Tsagarakis et al. 2010; Gulf of Lions: Bănaru et al. 2013; Tunisia: Hattab et al. 2013). In particular, the output of these models was used as a starting point for the reconstruction of those parameters for which information was lacking. Detailed descriptions of the functional groups and data used to parameterize the model are given in Tables S1-S5 in the Supplement. 
The official landing data by species and by country were taken from the United Nation's Food and Agriculture Organization (FAO) database (FishStat: http:// data.fao.org/database?entryId=babf3346-ff2d-4e6c9a40-ef6a50fcd422) and available from 1950 to 2010. This time series was then complemented with data (available per country) from the Sea Around Us database (www.seaaroundus.org) to assign species to fishing fleet. We considered 6 commercial fisheries defined by gear types: bottom trawlers, bottom dredges, mid-water trawlers, purse seiners, long liners and the artisanal fisheries. Species were assigned to the following gear types by assuming the same proportion per year as observed in the Sea Around Us database (data accessed in November 2013). In the case of Italy, which is surrounded by 3 of the 4 MSFD areas, we used a detailed reconstruction of catches (Piroddi et al. 2014) available for sub-regional seas ([MFSD area 1] Ligurian; [2] Northern, Central and Southern Tyrrhenian; [3] Ionian; [4] Northern, Central and Southern Adriatic Sea; [3] Sicilian; and [4] Sardinian waters), while for Greece, which has waters both in the Ionian and in the Eastern Mediterranean Sea, we used the same proportions as calculated by Tsikliras et al. (2007, 2013a). A recreational fishery was also included in the analysis using data coming from the Sea Around Us database (in the case of Italy and Spain) and from literature reviews (Anagnopoulos et al. 1998, Gordoa et al. 2004, Pawson et al. 2007, Cisneros-Montemayor \& Sumaila 2010). We estimated the percentage of discards and the species discarded using reports and scientific papers available in the literature (Megalofonou 2005, EC 2011, Vassilopoulou 2012, Tsagarakis et al. 2013) and data from previous EwE Mediterranean models available cited above. Fisheries landings and discards, expressed as annual rates $\left(\mathrm{t} \mathrm{km}^{-2} \mathrm{yr}^{-1}\right)$, for both models and for each subregion are shown in Tables S8-S11 in the Supplement. A list of functional groups and fisheries included in both models, together with their abbreviations, is given in Table 1 and in Table S5.

\section{Pedigree index and model quality}

The pedigree of the data refers to the uncertainty associated with the input values of the model. In general, higher pedigrees are associated with higher levels of data quality and with data coming from the study areas. Ecopath can take the pedigree values for all of the data entered in the model (e.g. biomass, $P / B, Q / B$, diets) into account and can calculate an overall pedigree index, ranging from 0 to 1 . Lower pedigree values imply a model constructed with lowprecision data and with data coming from areas outside the studied region, while higher values indicate a model constructed with locally-derived data (Morissette 2007, Christensen et al. 2008). Thus, to assess the quality of our input data, we calculated the overall pedigree index for both models. In addition, the pedigree was also used to guide the balancing procedure of both models, such that the lower pedigree inputs were the first to be modified while balancing the models.

\section{Model analysis and indices}

Trophic flows in terms of total production, consumption, respiration, catches and flow to detritus were estimated to represent ecosystem structure and exploitation status (Odum 1969, Ulanowicz 1986, Christensen \& Pauly 1993). In particular, the following indicators were evaluated: (1) Total system throughput (TST), calculated as the sum of all flows as an indication of the whole ecosystem size. (2) Total primary production/ total system respiration (TPP/TR) and total primary production/total biomass (TPP/TB), as a metric of system maturity. (3) Finn's cycling index (FCI), as the percentage of flows recycled in the food web (Finn 1976), and the predatory cycling index (PCI), as the percentage of production recycled after the removal of detritus (Christensen et al. 2008). (4) Ascendancy (A), as a measurement of system growth and development of network links (Monaco \& Ulanowicz 1997). (5) Overhead (O), as the energy in reserve of an ecosystem that reflects the system's strength when it experiences unexpected perturbations (Ulanowicz 1986). (6) System omnivory index (SOI), based on the average omnivory index (OI), which is calculated as the variance of the trophic levels (TLs) of a consumer's prey groups indicating predatory specialization (Christensen \& Pauly 1993). (7) Mean transfer efficiency (TE), as the efficiency in which energy is transferred between TLs. The mean TE is calculated as the geometric mean of TE for each of the integer TLs II to IV. (8) TL of each functional group expressed as:

$$
T L_{j}=1+\sum_{i=1}^{n} D C_{j i} \cdot T L_{i}
$$

where $j$ is the predator of prey $i, D C_{j i}$ is the fraction of prey $i$ in the diet of each predator $j$, and $T L_{i}$ is the TL of prey $i$. By definition, TL I is attributed to primary producers and detritus, TL II to herbivores, TL III to first-order carnivores and TL IV to second-order carnivores. (9) TL of the catches $\left(T L_{C}\right)$, as: 


$$
T L_{C i}=\frac{\sum_{i=1}^{n} T L_{i} \cdot Y_{i}}{\sum_{i=1}^{n} Y_{i}}
$$

where $Y_{i}$ refers to the landings of species (group) $i$. (10) Primary production required (PPR) to sustain the catch, to evaluate the sustainability of fisheries (Pauly \& Christensen 1995).

To better represent trophic flows, TLs and biomasses of the Mediterranean marine ecosystem, we used 2 different graphical representations: a flow diagram and a Lindeman spine (Lindeman 1942, Ulanowicz 1995). In the Lindeman spine, primary producers and detritus (both with $\mathrm{TL}=1$ ) were separated to better represent the different flows going to the different compartments. To highlight differences in total biomass and mean TL of the community, we also plotted these 2 variables for each MSFD area for the 2 time periods.

\section{Mixed trophic impact and keystone species analyses}

The mixed trophic impact (MTI) analysis, expressed as:

$$
M T I_{i j}=D C_{i j}-F C_{j i}
$$

where $D C_{i j}$ is the diet composition term expressing how much $j$ contributes to the diet of $i$, and $F C_{j i}$ is the proportion of predation on $j$ that is due to $i$ as a predator, allows the quantification of the impacts that a theoretical change of a unit in the biomass of a group (including fishing activities) would have on other groups in the ecosystem (Christensen et al. 2008). It can assess both direct and indirect trophic impacts in the food web, which are either positive or negative, indicating an increase or decrease in the quantity of the affected group. Here we looked at the MTI for each MSFD area and for the 2 different time periods. In addition, and building from the MTI analysis, the keystoneness index (KS) assesses the potential roles of each functional group as keystones in the system. Normally, keystone species are species with a relative low biomass but whose biomass changes would have a disproportionately large effect on the ecosystem structure (Power et al. 1996). Here, for both time periods, we used the index proposed by Libralato et al. (2006):

$$
K S_{i}=\log \left(\varepsilon_{i} \times 1 / p_{i}\right)
$$

where $\varepsilon_{i}$ is the overall effect expressed as the square root of the sum of $m_{i j}$ square (with $m_{i j}$ being the rela- tive impact of a slight increase in biomass of impacting group $i$ on biomass of impacted group $j$ ), and $p_{i}$ is the contribution of the functional group to the total biomass of the food web.

\section{Comparison with other European regional seas models}

In an effort to support the MSFD, we compared a selection of ecological, fishing and network analysis indicators derived from the Mediterranean Sea model with those obtained from Ecopath models built for other European regional seas: the North Sea (Mackinson 2014), the Baltic Sea (Tomczak et al. 2012, 2013) and the Black Sea (Akoglu et al. 2014). This comparative analysis was done to obtain an overview, at the European scale, of similarities and differences between these exploited ecosystems. We are aware that a few limitations in confronting these models may occur due to differences in model criteria and construction (e.g. definition of certain groups, time periods), and for this reason we present model results with structural differences of the models for a better interpretation of the analysis. In addition, only those indicators more robust to model configurations (e.g. TST, mean TL of the catch, PPR to sustain fisheries, ascendancy and overhead; see Table 2 for the complete list of indicators), as previously assessed by Moloney et al. (2005) and Heymans et al. (2014), were used for the comparison.

\section{RESULTS}

\section{Functional group input, data quality and mass balancing}

Each MSFD area had 26 living groups (i.e. excluding detritus and discards), if we also consider the 3 migratory groups as part of each area. Of those 26 groups, the main mass-balancing problems were encountered among 'other small' and 'medium' pelagic fishes, 'small' and 'medium' demersal fishes, 'European pilchard' and 'anchovy', 'benthopelagic cephalopods', 'crustaceans', 'benthos' and 'zooplankton', with $E E$ values $>1$. To obtain mass balance for these groups, we primarily adjusted the diet matrix as the data source with higher uncertainty. For instance, the predation caused by 'large pelagic fish' on 'European pilchard' and 'anchovy', 'medium' and 'other small' pelagic fishes and 'benthopelagic 
cephalopods' was too high and was reduced. Similarly, the consumption of 'other cetaceans', 'benthopelagic' and 'benthic cephalopods', 'large' and 'medium demersal fishes', 'sharks' and 'rays and skates' on the 'crustaceans' group was overestimated and was reduced by redistributing the proportions in the predators' diets. Biomasses of 'crustaceans' and 'bivalves and gastropods' were the only biomasses that were modified from the original input data. The biomasses of these groups were indeed too low and had to be increased. This is a common problem in prebalanced EwE models, where invertebrate biomass estimates are frequently too low to support predation mortality (Christensen et al. 2008).

Once balanced, EE values were high for the majority of the functional groups, indicating that total mortality in the system was mainly driven by predation and fishing. The gross food conversion efficiency $(P / Q)$ and the respiration over assimilation $(R / A)$ were within the expected ranges (Christensen et al. 2008). The resulting output parameters and the final diet matrix are shown for each model in Tables S1-S4 in the Supplement.

Pedigree indices were different for each time period and increased from the 1950s (0.391) to the 2000s (0.594). Individual results of the pedigree index can be found in Table S7 in the Supplement.

\section{TLs and flows}

Trophic flows, TLs and relative biomasses of the Mediterranean Sea ecosystem for the 2000s model are represented in Fig. 2 and in Table S6 (flow diagrams) in the Supplement. In the latter, flow diagrams are separated for each MSFD area. Functional groups are illustrated by their TLs ranging from 1 (primary producers) to 4.22 (marine mammals); the highest TLs were found for 'piscivorous cetaceans' and 'monk seals' (TL $\geq 4$ ). The other marine mammal group, 'other cetaceans', showed a TL of 3.53 (mainly because of the presence of 'zooplankton' and 'benthopelagic cephalopods' in their diet). 'Seabirds', despite being considered a top predator, showed a relatively low TL due to the presence of discards (mainly small pelagic fishes, Oro \& Ruiz 1997, Bozzano \& Sardà 2002) in their diet. Similarly, 'sea turtles' might have a higher TL than estimated by the model, but their diet also includes discards (Tomas et al. 2001, Gómez de Segura et al. 2003, Casale et al. 2008), and thus, they presented a fairly low TL (2.68) in the model. This is an artifact of EwE that considers discards as a detritus group with $\mathrm{TL}=1$ and thus tends to lower the TL of those groups that feed considerably on discards (Christensen et al. 2008), as previously seen in other food web models of Mediter-

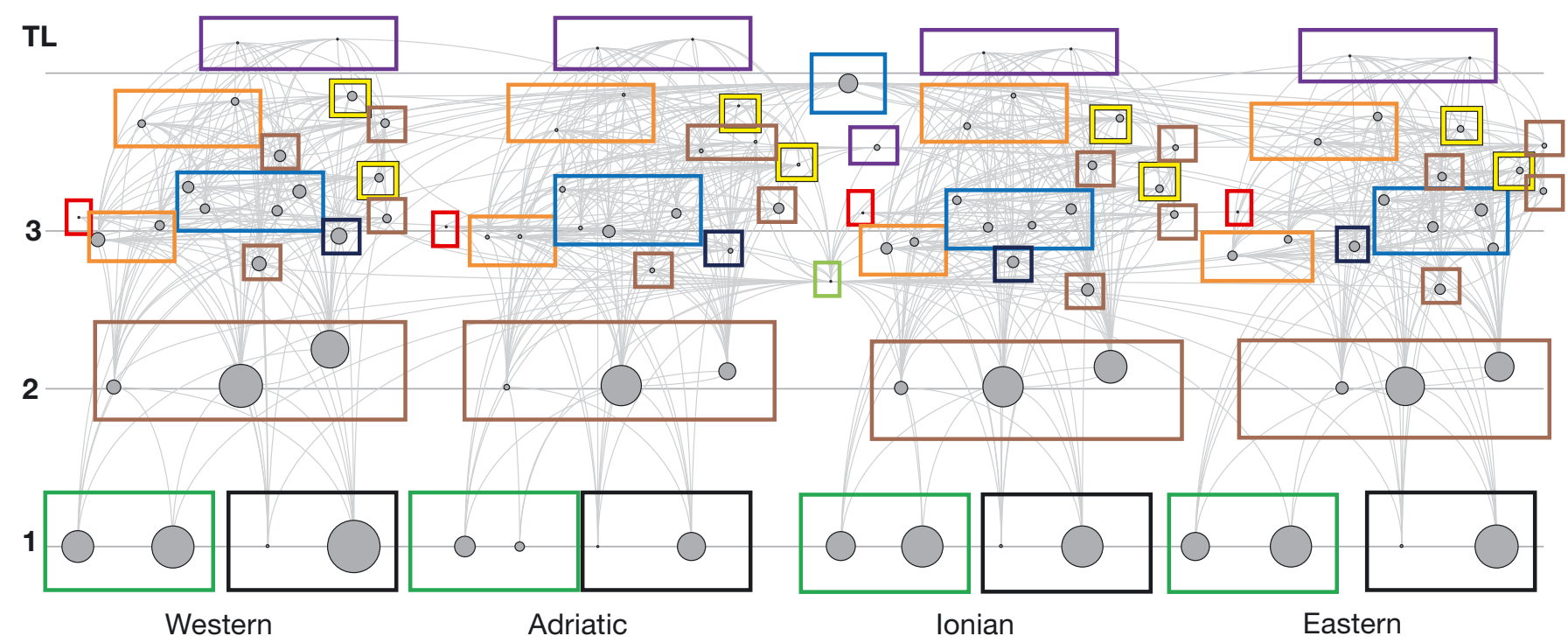

Fig. 2. Flow diagram of the Mediterranean Sea ecosystem (in the 2000s) with the Western part being at the far left followed by the Adriatic, the Ionian and the Eastern (see Fig. 1). Each functional group is shown as a circle whose size is approximately proportional to the log of its biomass. All functional groups are represented by their trophic levels (TL; $y$-axis) and linked to each other by predator-prey relationships expressed as light grey lines. Coloured boxes define the main functional groups: marine mammals (purple); pelagic fishes (blue); demersal fishes (orange); sharks/rays and skates (yellow); deep-sea fishes (dark blue); seabirds (red); invertebrates (brown); sea turtles (light green); primary producers (dark green); detritus groups (black). Individual flow diagrams of the 4 Marine Strategy Framework Directive (MSFD) areas are presented in Table S6 in the Supplement at www.int-res.com/articles/suppl/m533p047_supp.pdf 
ranean areas (Coll et al. 2006, 2007, Piroddi et al. 2010). For the fish groups, 'large pelagic fishes' showed a relatively high TL (3.94), followed by 'European hake' (between 3.86 and 3.73), 'large demersal fishes' (between 3.68 and 3.56), 'sharks' (between 3.85 and 3.64) and 'rays and skates' (between 3.41 and 3.27). 'Medium' and 'other small' pelagic fishes were given a TL between 3.28 and 3.19 and between 3.14 and 2.89, respectively. 'European pilchard' and 'European anchovy' had TL values ranging between 3.25 and 3 , while the lowest TLs were observed for 'medium' and 'small' demersal fishes and 'deep-sea fishes' (between 3.04 and 2.80). Of the remaining functional groups, 'benthopelagic' and 'benthic cephalopods' and 'jellyfish' reached TL $>3$, 'crustaceans' showed values between 2.79 and 2.63, and 'zooplankton', 'bivalves and gastropods' and 'benthos' had TL values close to 2 .

Looking at the 4 MSFD areas, comparing total biomass and mean TL of the community, the Adriatic and the Western Mediterranean Sea were the areas with the highest total biomass, followed by the Ionian and Eastern Seas (Fig. 3). During the 2000s, the mean TL of the community (TLCo) differed considerably whether calculated using TLco $\geq 1$ or TLco $>1$ (i.e. excluding detritus and primary producers). For TLco $\geq 1$, the Adriatic was the area with highest mean TLco (1.86) followed by the Ionian (1.56), Eastern (1.5) and Western Mediterranean (1.49). For TLco > 1 , the Western had the highest TLco (2.36), followed by the Eastern (2.34), Ionian (2.28) and Adriatic Seas

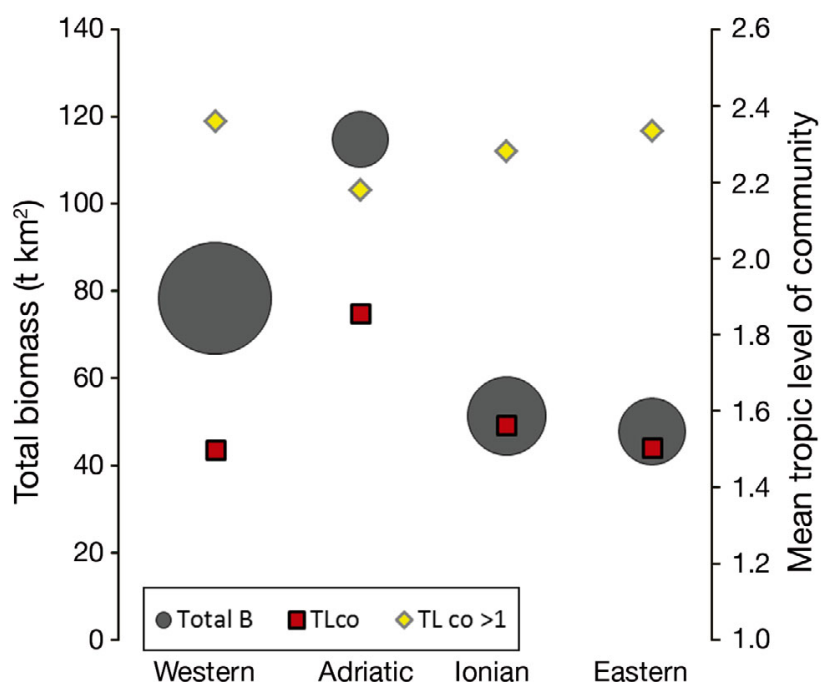

Fig. 3. Total biomass and mean trophic level of the community (TLCo) with and without detritus and primary producers (TLco > 1) for each MSFD area (see Fig. 1) for the 2000s. Total biomass is shown as a circle whose size is proportional to the area of the MSFD
(2.18) (Fig. 3). Several differences in TLs were also found between the 2 modelled time periods, with declines observed particularly in the Ionian and Eastern Mediterranean Sea in the 2000s compared to the 1950s (Fig. 4). However, to be able to assess changes in TL of the community in the Mediterranean Sea, a more accurate analysis is needed (such as fitting the model to time series data that will reduce the noise around the parameters; Christensen \& Walters 2004).

In the Lindeman spine analysis (Fig. 5), similar patterns were observed for both time periods. Most trophic flows fell within TL I, II and III, and TL I was the pool that generated the majority of the total system throughput (1950s: $78.4 \%$ and 2000 s: $79.3 \%$ ) followed by TL II, with $20.2 \%$ for the 1950 s and $19.6 \%$ for the 2000s. In both time periods, primary producers and TL II organisms had the highest biomasses, and comparing the 2 decades, a decline in biomasses was observed in the 2000 s versus the 1950 s particularly for those groups having TLs higher than III. In both systems, exports as catches were mainly concentrated within TL III.

\begin{tabular}{|c|c|c|c|c|c|}
\hline \multirow[b]{2}{*}{ Group names } & \multicolumn{5}{|c|}{ TL2000s/TL1950s } \\
\hline & $\mathbf{W}$ & A & I & $E$ & $\mathbf{M}$ \\
\hline \multicolumn{6}{|c|}{ Piscivorous cetaceans } \\
\hline \multicolumn{6}{|c|}{ Pinnipeds } \\
\hline \multicolumn{6}{|l|}{ Seabirds } \\
\hline \multicolumn{6}{|c|}{ Medium pelagic fishes } \\
\hline \multicolumn{6}{|c|}{ European pilchard } \\
\hline \multicolumn{6}{|c|}{ European anchovy } \\
\hline \multicolumn{6}{|c|}{ Other small pelagic fishes } \\
\hline \multicolumn{6}{|c|}{ Large demersals } \\
\hline \multicolumn{6}{|c|}{ European hake } \\
\hline \multicolumn{6}{|c|}{ Medium demersal fishes } \\
\hline \multicolumn{6}{|c|}{ Small demersal fishes } \\
\hline \multicolumn{6}{|c|}{ Deep-sea fishes } \\
\hline \multicolumn{6}{|l|}{ Sharks } \\
\hline \multicolumn{6}{|c|}{ Rays and skates } \\
\hline \multicolumn{6}{|c|}{ Benthopelagic cephalopods } \\
\hline \multicolumn{6}{|c|}{ Benthic cephalopods } \\
\hline \multicolumn{6}{|c|}{ Bivalves and gastropods } \\
\hline \multicolumn{6}{|c|}{ Crustaceans } \\
\hline \multicolumn{6}{|l|}{ Jellyfish } \\
\hline \multicolumn{6}{|l|}{ Benthos } \\
\hline \multicolumn{6}{|l|}{ Zooplankton } \\
\hline \multicolumn{6}{|l|}{ Other cetaceans } \\
\hline Sea turtles & & & & & \\
\hline Large pelagics & & & & & \\
\hline
\end{tabular}

Fig. 4. Changes in trophic levels (TLs) between the 1950s and the 2000s for each functional group for each Marine Strategy Framework Directive (MSFD) area (W: Western; A: Adriatic; I: Ionian/Central; E: Aegean/Levantine) and the whole Mediterranean Sea (M: Mediterranean). Green cells represent increased TLs $(>0)$, yellow cells indicate stable TLs $(=0)$, and red cells show decreased TLs $(<0)$. Grey cells indicate 'not applicable' 


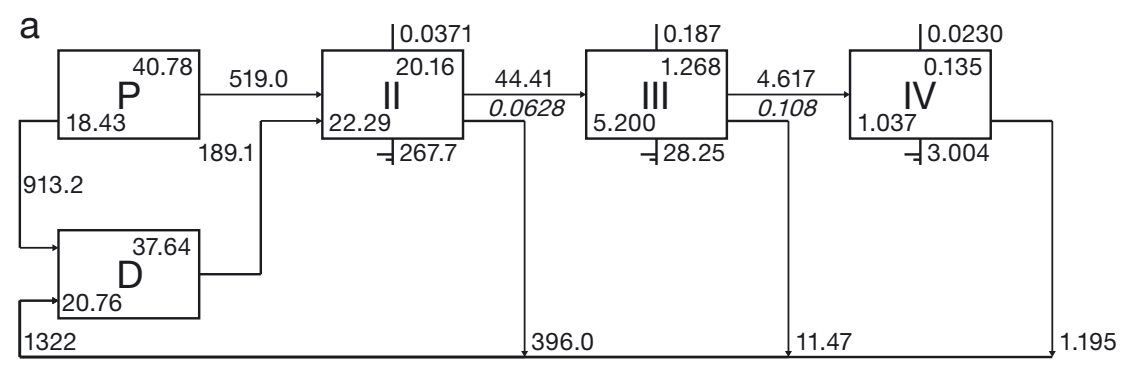

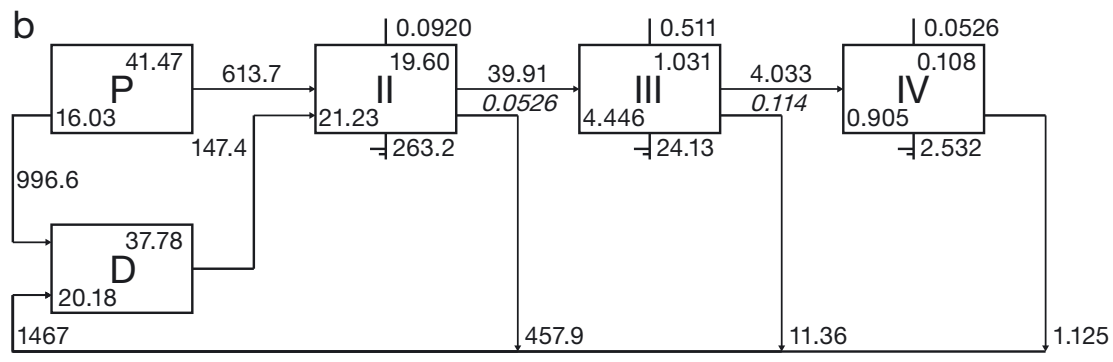

Fig. 5. Lindeman spine representation of trophic flows $\left(\mathrm{t} \mathrm{km} \mathrm{km}^{-2} \mathrm{yr}^{-1}\right.$ ) and biomasses (t $\mathrm{km}^{-2}$ ) for the entire Mediterranean Sea ecosystem for (a) the 1950s and (b) the 2000s. P: primary producers; D: detritus (both TLI). TST\%: total system throughput; TE: transfer efficiency

\section{Trophic impact and keystone species}

For a better interpretation of the MTI analysis, results are presented separating each MSFD area (Fig. 6). Several general patterns can be observed in all 4 areas. Among all MSFD areas, most predators had a direct negative impact on their prey through their diet preferences; functional groups negatively impacted themselves due to cannibalism/withingroup competition; demersal functional groups had a greater impact (either negatively or positively) on the majority of the other groups than pelagic functional groups, and 'zooplankton' and 'phytoplankton' groups most positively affected all other groups in the system (e.g. through a bottom-up effect).

MTI analysis in both time periods revealed changes in the role of 'pinnipeds' in the West, Adriatic and Ionian Seas, with a higher impact in the food web during the 1950s and almost no impact in the 2000s. In the Eastern Mediterranean, where the species still occurred in greater numbers, the impact on the food web was greater in 2000s than in the other 3 MSFD areas but still reduced compared to the 1950s. Similar trends were observed for 'piscivorous cetaceans' in all MSFD areas, where the group had a large effect in the 1950s but because of their reduced biomass, only had a limited effect in the 2000s. For fishes, 'European anchovy' and 'European pilchard' similarly affected the Mediterranean food web with greater positive impact on top predators, pelagic fishes and fisheries (particularly mid-water trawlers and purse seiners). Interestingly, 'sharks' were negatively impacting marine mammals either through direct competition for the same resources or niche overlap. Overall, lower TL organisms, namely 'benthos', 'crustaceans' and particularly 'seagrass', positively affected the rest of the food web.

Results also revealed that the role of fisheries in the different MSFD areas has changed with time, growing in impact from 1950s to 2000s, and affecting several groups in the different food webs. In general, if only the commercially exploited functional groups were considered, results showed a greater impact of bottom trawlers, mid-water trawlers and purse seiners (Fig. 7b). More specifically, bottom trawlers and dredges had large negative impacts on targeted demersal species (mainly demersal fishes and 'molluscs') and on 'sea turtles' (incidental catches), while longline fisheries had large negative impacts on 'large pelagic fishes' (target species) and, through incidental catches, on 'sea turtles', dolphins and 'seabirds'. Mid-water trawlers and purse seiners showed negative impacts on targeted small pelagic fishes and, through direct competition for the same resources, on marine mammals and 'seabirds'. When all functional groups in the ecosystem were included in the analysis, artisanal fisheries seemed to be the fleets with greater negative impact, particularly in the Western, Ionian and Eastern Mediterranean Seas (Fig. 7a). Recreational fisheries had a negative impact on 'large pelagic fishes' and 'sharks' in the Western, Adriatic and Ionian Seas and on 'medium' and 'small' demersal and 'medium' and small pelagic fishes in the Eastern Mediterranean.

The results obtained from the keystoneness analysis (Fig. 8 and Table S6 in the Supplement) revealed that in the 1950s ecosystem, 'large pelagic fishes' had the highest overall keystoneness role followed by 'sharks' and 'medium pelagic fishes' groups, whereas in the 2000s ecosystem, 'medium pelagic fishes' were replaced by 'benthic' and 'benthopelagic cephalopods'. Interestingly lower TL groups (e.g. 'zooplankton', 

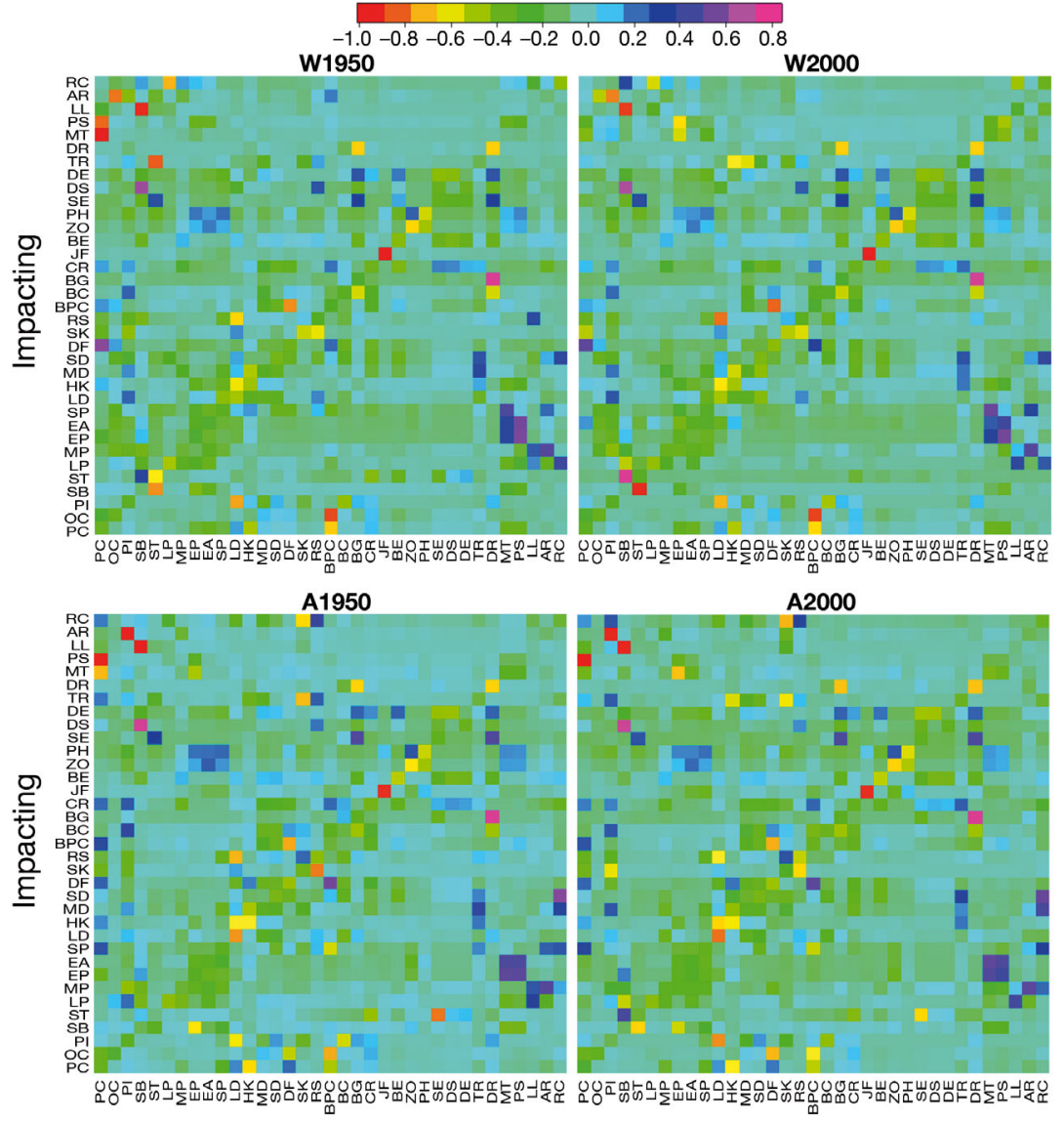

11950
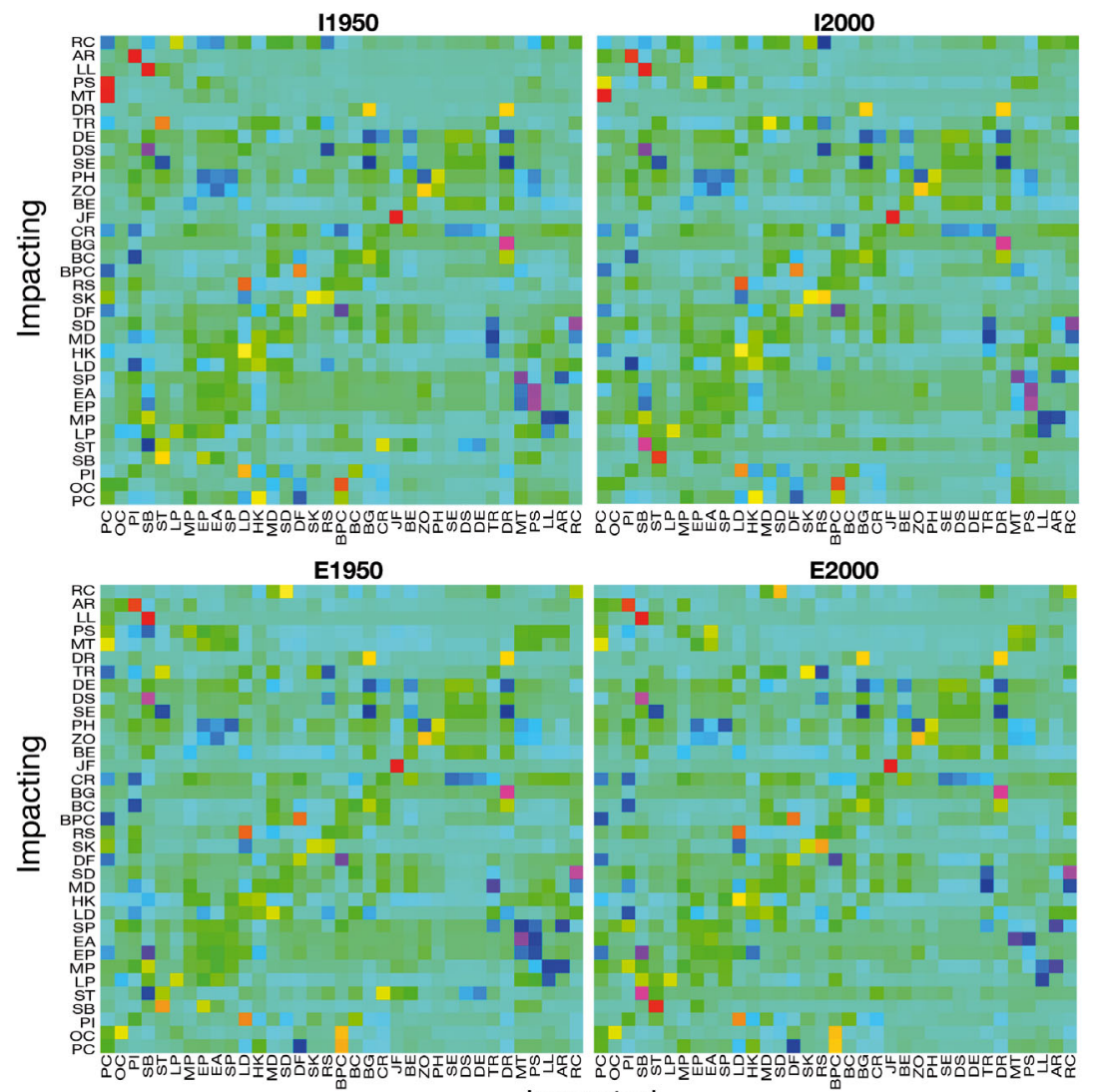

Impacted 'phytoplankton' and 'benthos') were also identified in both time periods as keystone groups, probably caused by their overall low biomass and high $P / B$ (characteristic of oligotrophic systems) and important role in the ecosystem. In both time periods, marine mammals, in particular 'pinnipeds' and 'piscivorous cetaceans', appeared within the least important keystone groups.

\section{Comparison among European regional seas}

The statistics and main indicators calculated from the whole Mediterranean Sea ecosystem model representing the 2000s were compared with other modelled European regional seas for the same or similar period (Table 2). The TST revealed that the main flows driving the Mediterranean Sea were flow to detritus $(42 \%)$ and exports $(39 \%)$ followed by consumption $(15 \%)$ and respiration (5\%). In the Baltic, North and Black Seas, on the other hand, consumption seemed to be the flow with the highest importance (around 43-48\%) followed by flow to detritus (22-30\%), respiration $(20-23 \%$; in the Black Sea, this flow constituted the second most important flow, with $29 \%$ ) and exports $(1-6 \%)$.

Looking at ecological indicators addressing community energetics and cycling of nutrients, under Odum's theory (Odum 1969), our results sug-

Fig. 6. Mixed trophic impact relationships between functional groups and fisheries in the 4 different Marine Strategy Framework Directive (MSFD) areas (W: Western; A: Adriatic; I: Ionian/Central; E: Aegean/ Levantine). Positive values (from light blue to purple) indicate positive impacts; negative values (from light green to red) indicate negative impacts. The colors should not be interpreted in an absolute sense: the impacts are relative, but comparable between groups. For group abbreviations, refer to Table 1 

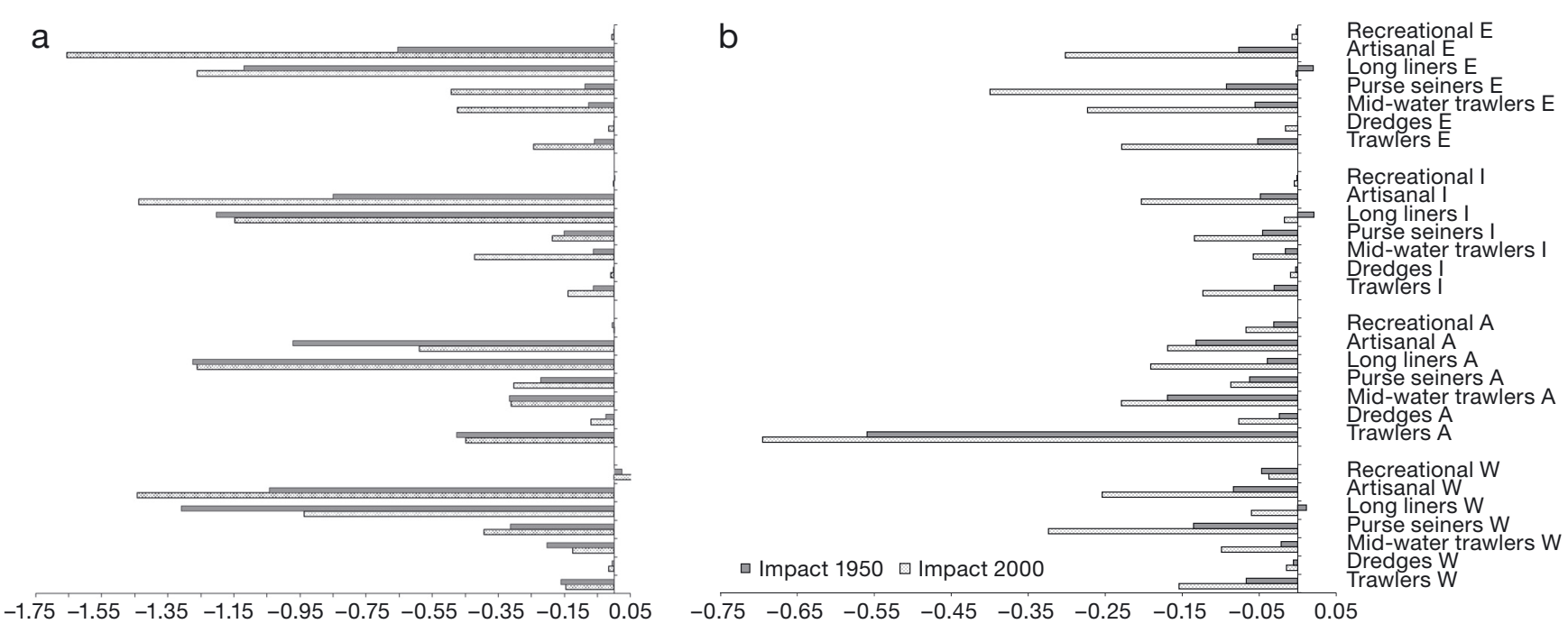

Fig. 7. Cumulative impact (either direct or through a cascade effect) of each fishing gear on (a) all functional groups of the ecosystem and (b) all commercially important species/groups of the ecosystem (see Table 1, numbers 6 to 14 and 16 to 21 ), in the different Marine Strategy Framework Directive (MSFD) areas (see Fig. 1) and for each studied period. The cumulative impacts were calculated from the mixed trophic impact calculations. Negative values on the $x$-axis represent negative impact to a positive change in fishery harvest

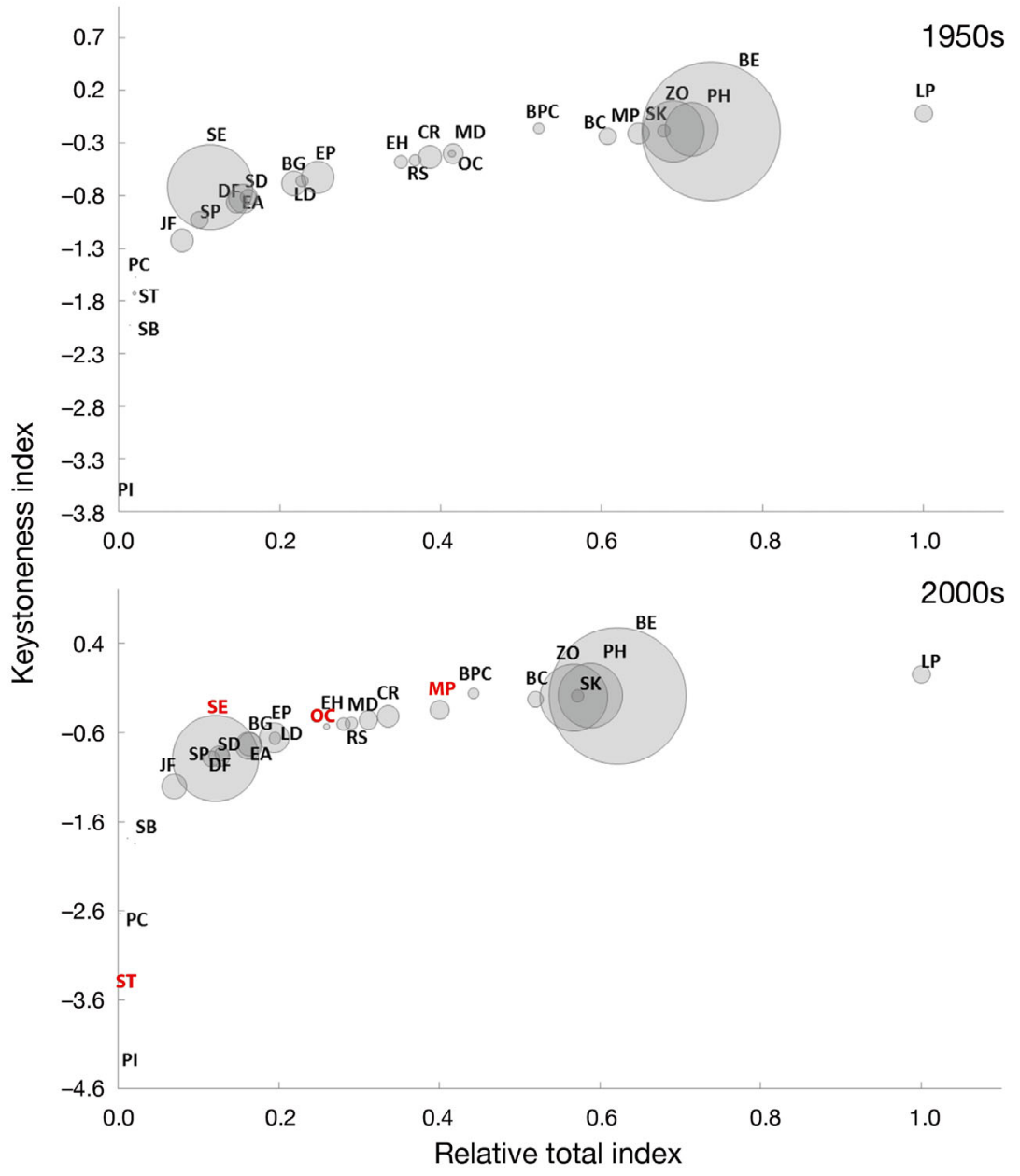

gest that the Mediterranean Sea ecosystem is at an early developmental stage. This was visible, for example, in the ratio between total primary production (PP) and total respiration (R) (Odum 1969, Christensen 1995) or in the primary production/biomass ratio $(\mathrm{PP} / B)$. On the other hand, the indicators from the other European Seas suggested that systems fell within an intermediate-low level developmental stage. For the SOI, despite the low general values, the Mediterranean Sea showed the highest value, while in relation to the 2 cycling indices, the Mediterranean basin had the highest values in PCI and the lowest in FCI. For each European regional sea, ascendancy was relatively low, whereas

Fig. 8. Relative total impact $\left(\varepsilon_{i}\right)$ versus keystoneness $\left(K S_{i}\right)$ showing the role of species/groups in the ecosystem for both time periods (1950s and 2000s). The size of the circles is proportional to the species/group biomass. Functional groups that showed a decline in their keystone role in comparison to the 1950s are shown in red. For abbreviations, refer to Table 1 
Table 2. Summary statistics for the Mediterranean Sea food web model in comparison with the North Sea, Baltic Sea and Black Sea

\begin{tabular}{|c|c|c|c|c|c|}
\hline Indicators & $\begin{array}{c}\text { Mediterranean } \\
\text { Sea } \\
\text { (this study) }\end{array}$ & $\begin{array}{c}\text { North Sea } \\
\text { (Mackinson } \\
\text { et al. 2014) }\end{array}$ & $\begin{array}{l}\text { Baltic Sea } \\
\text { (Tomczak } \\
\text { et al. 2012) }\end{array}$ & $\begin{array}{c}\text { Black Sea } \\
\text { (Akoglu } \\
\text { et al. 2014) }\end{array}$ & Units \\
\hline \multicolumn{6}{|l|}{ Main ecosystem features } \\
\hline Area & 2512000 & 570000 & 240000 & 150000 & $\mathrm{~km}^{2}$ \\
\hline Studied period & 2000 s & 1991 & $2000 s$ & $1995-2000$ & Year \\
\hline Functional groups & 103 & 68 & 21 & 10 & No. \\
\hline \multicolumn{6}{|l|}{ Main indicators } \\
\hline Sum of all consumption & 923 & 6157 & 3435 & 4500 & $\mathrm{t} \mathrm{km}^{-2} \mathrm{yr}^{-1}$ \\
\hline Sum of all exports & 1320 & 105 & 476 & 490 & $\mathrm{t} \mathrm{km}^{-2} \mathrm{yr}^{-1}$ \\
\hline Sum of all respiratory flows & 290 & 2658 & 1851 & 2990 & $\mathrm{t} \mathrm{km}^{-2} \mathrm{yr}^{-1}$ \\
\hline Sum of all flows into detritus & 1467 & 3867 & 2246 & 2230 & $\mathrm{t} \mathrm{km}^{-2} \mathrm{yr}^{-1}$ \\
\hline Total system throughput & 4000 & 12786 & 8007 & 10210 & $\mathrm{t} \mathrm{km}^{-2} \mathrm{yr}^{-1}$ \\
\hline Mean trophic level of the catch & 3.08 & 3.7 & 3.30 & 3 & \\
\hline Gross efficiency (catch/net primary production) & 0.00026 & 0.00226 & 0.0016 & 0.001 & \\
\hline Total primary production & 1610 & 2609 & 2434 & 3483 & $\mathrm{t} \mathrm{km}^{-2} \mathrm{yr}^{-1}$ \\
\hline Total primary production/total respiration & 5.55 & 0.98 & 1.26 & 1.16 & \\
\hline $\begin{array}{l}\text { Primary production required to sustain fisheries } \\
\text { (PPR, considering primary production) }\end{array}$ & 1.46 & 5.88 & 52.57 & 28.93 & $\%$ \\
\hline Total primary production/total biomass & 37.67 & 4.71 & 22.54 & 90 & \\
\hline Total biomass (excluding detritus) & 42.74 & 554 & 108 & 38.7 & $\mathrm{t} \mathrm{km}^{-2}$ \\
\hline Connectance index & 0.10 & 0.22 & 0.22 & 2.5 & \\
\hline System omnivory index & 0.27 & 0.23 & 0.15 & 0.116 & \\
\hline Predatory cycling index & 10.96 & - & 0.41 & - & $\%$ \\
\hline Finn's cycling index & 4.98 & 20.24 & 6.98 & 15.01 & $\%$ \\
\hline Mean transfer efficiency & 9.2 & 30.2 & 12 & 7.4 & $\%$ \\
\hline Ascendancy & 42.9 & 20.6 & 30.82 & 31.7 & $\%$ \\
\hline Overhead & 57.1 & 79.4 & 69.18 & 68.3 & $\%$ \\
\hline
\end{tabular}

overhead was high. The mean TE observed in the Mediterranean Sea was similar to the Baltic Sea but was lower in comparison to values calculated for the Black and North Seas. As for fishing indicators, the PPR \% of the Mediterranean was $0.81 \%$, the lowest among the other seas, while $T L_{c}$ was 3.04 in the Mediterranean Sea, similar to the Black Sea and lower in comparison to the other European Seas with higher TL values (between 3.3 and 3.7).

\section{DISCUSSION}

This study constitutes the first attempt to build an historical and current food web model for the whole Mediterranean Sea with the challenging effort to integrate available spatial and temporal (in terms of comparing the 1950s and 2000s) biological data and modelling outputs in a coherent manner. We acknowledge that data gaps still exist, for example on temporal changes in diet composition, temporal estimates of discards and biomasses of non-commercially important species and deep-sea organisms. Thus, further efforts should be made to reduce this uncertainty and increase the quality of these models.

\section{Quality of the models}

As expected, the 1950s model showed a lower pedigree index, scoring in the lower range (0.1640.676) when compared to the 150 balanced EwE models previously assessed globally by Morissette (2007). This is because the 1950s model was constructed using mainly data obtained from other modelling approaches (e.g. biogeochemical models to estimate phytoplankton biomasses and stock recruitment models to estimate biomass of fish stocks; refer to Table S5 in the Supplement for details of each functional group). Models that have tried to represent the past have always been associated with higher uncertainty, as was observed in other studies (Coll et al. 2008, 2009c, Piroddi et al. 2010, Christensen et al. 2014, Macias et al. 2014), and their outputs should be always taken with caution. To limit this uncertainty, we tried to use models for which outputs have been tested and when possible validated (Macias et al. 2014), or that have been widely utilized to assess temporal biomasses as done for fish stocks (e.g. surplus production models; Walters et al. 2008, Piroddi et al. 2011). In contrast, the 2000s model, due to its higher data quality, showed a rela- 
tively higher pedigree. This was due to the availability, in more recent years, of survey data (e.g. trawl surveys such as the MEDITS campaign) and the increase in biodiversity assessments (e.g. Coll et al. 2010) that have improved the level of knowledge in the basin. Nevertheless, data deficiencies exist, particularly in African and Arabic countries, where survey data remain either inaccessible or absent. Despite these limitations, the models developed in this study represent an important step towards an integrated understanding of the Mediterranean Sea marine ecosystem structure and function.

\section{Biomasses, trophic flows and TLs}

Results presented here show how the Mediterranean Sea is mainly dominated, in terms of biomass, by lower TL organisms, particularly 'benthos', 'zooplankton' and 'phytoplankton'. These groups dominate most of the system flows and, as observed at smaller scales in other Mediterranean food web models (Coll et al. 2006, 2007, Tsagarakis et al. 2010, Moutopoulos et al. 2013, Torres et al. 2013), constantly appear as important key species. This is probably because of the relatively low biomass at higher TLs and a relatively high mean TE overall in the food web, in line with previous studies (Pauly \& Christensen 1995, Coll \& Libralato 2012). This phenomenon is called the 'Mediterranean paradox' for the fact that despite the oligotrophic condition of the basin that constrains the reproduction and feeding of zooplankton, the ecosystem is capable of producing a relatively high fish abundance (Sournia 1973, Macias et al. 2014). In addition, the high TEs have been suggested as a sign of overexploitation of the Mediterranean Sea due to high production exports (Coll et al. 2009b).

Marine mammals and large pelagic fishes, on the other hand, are the top predators of the Mediterranean marine ecosystem. In particular, the Mediterranean monk seal Monachus monachus is the species with the highest TL followed by 'piscivorous cetaceans' and 'large pelagic fishes'. These outcomes are very interesting since the Mediterranean monk seal and several dolphin populations (e.g. the shortbeaked common dolphin Delphinus delphis) have dramatically declined over the centuries because of a variety of anthropogenic pressures (e.g. fisheries interactions, habitat loss and pollution) and are now classified either as Critically Endangered (the Mediterranean monk seal is almost extinct), Endangered, or Vulnerable by the International Union for Conser- vation of Nature (IUCN) Red List of Threatened Animals (UNEP/MAP 1994, Johnson \& Lavigne 1998, Reeves \& Notarbartolo di Sciara 2006, Bearzi et al. 2008, Piroddi et al. 2011).

Large pelagic fishes (mainly tuna species and swordfish), the main keystone group in our modelling approach, have consistently been exploited for thousands of years in the Mediterranean Sea, and these species are also at low levels of abundance (Abdul Malak et al. 2011). This severe decline in biodiversity at the top of the food web particularly in recent decades (Briand 2000, Bearzi et al. 2008, Coll et al. 2008, 2009c, Piroddi et al. 2010, 2011, Lotze et al. 2011), as also shown in our study by their reduced biomass levels, could have induced a cascade effect throughout the food web, with effects on the complexity, connectivity and robustness of the system against further species loss (Briand 2000, Heithaus et al. 2008, Lotze et al. 2011, Piroddi et al. 2011). Defined as umbrella, sentinel, keystone or flagship species, they reflect ecosystem changes and degradation over time, as is also clear from our keystone and MTI analysis, and ensuring their survival would lead to ways of enhancing marine ecosystems and ensure sustainable human activities (Bossart 2006, Boyd et al. 2006, Trites et al. 2006, Sergio et al. 2008).

\section{Ecological role of species and changes with time}

The results of our keystone analysis for both time periods also revealed changes over time in other important keystone species. After 'large pelagic fishes', 'sharks' and 'medium pelagic fishes' have played a key role in the past ecosystem, replaced in more recent years by 'benthopelagic cephalopods'. This is not the first time that cephalopods have been identified as a keystone group in Mediterranean food webs (Coll et al. 2006, Tsagarakis et al. 2010, Bănaru et al. 2013, Hattab et al. 2013, Torres et al. 2013). This functional group, the role of which in the overall structure and functioning of marine ecosystems remains poorly understood, has an important trophic position (being both predator and prey), and because it can proliferate in highly exploited ecosystems, it constitutes a key element of present marine food webs (Pierce et al. 2008, Coll et al. 2013). As for 'sharks', particularly large predatory sharks, several studies have pointed at strong declines in species over the last centuries mainly due to intensive overexploitation (both for consumption and as discarded species; Megalofonou 2005, Ferretti et al. 2008, Maynou et al. 2011, Coll et al. 2014a). The present study 
suggests that these species were important in the past Mediterranean ecosystem and confirms a diminishing role within the current food web as a consequence of a reduction in their abundance.

Small and 'medium' pelagic fishes, both with high biomasses and high proportions in catches, show an important role in the Mediterranean ecosystem as structuring species of the food web (Coll et al. 2006, 2007, Piroddi et al. 2010, Tsagarakis et al. 2010). Yet, our results highlight how these organisms, despite being essential for transferring energy from lower to higher TL organisms (Cury et al. 2000, Pikitch et al. 2014), have diminished considerably between the 2 time periods and between sub-regions, causing a reduction in their ecological role.

\section{Fishing impact and the quality of data}

From the MTI analysis, bottom trawling and dredges were the fisheries with the widest impact on the food web, particularly on the demersal community. This has been observed in sub-areas of the Mediterranean Sea representing continental shelf and upper slopes (Coll et al. 2006, 2007, Bănaru et al. 2013, Hattab et al. 2013). Therefore, our results highlight the effect of bottom trawlers and dredges on marine resources and ecosystems of the Mediterranean Sea as an important issue that should be addressed if sustainable management of fisheries is to be achieved within the region (Puig et al. 2012). The impacts of artisanal fisheries on the ecosystem have also increased over time, particularly in the Ionian and Eastern Mediterranean Seas, and are probably caused by increased fishing effort in the EU, northern African and Arabic countries (Anticamara et al. 2011). This also has clear implications for the management of marine resources in the Mediterranean Sea because the artisanal fleet dominates the fishing activity in many Mediterranean countries but is poorly monitored.

Overall, our results show that over time, fisheries have exerted a negative pressure on the food web as a consequence of increased and intensive overexploitation. Yet, several interpretations of these results could be drawn: first, fisheries might not display a greater negative impact (than the one presented here) on commercially important species because of the inclusion in the analysis of developing countries (e.g. North African and Arabic countries) and developed countries together. Completely different spatiotemporal patterns/trends characterize these 2 sides of the Mediterranean Sea that might lead to a masking effect scenario. A reflection of this is visible in the increased impact of artisanal fisheries in the Ionian and Eastern Mediterranean Seas, possibly as a consequence of increased fishing effort in southern Mediterranean countries. This distortion might also be caused by discards, which we kept constant in time due to lack of information, and by Illegal, Unregulated, and Unreported IUU) activities that, despite being a serious issue in the Mediterranean Sea (Ulman et al. 2013, Coll et al. $2014 \mathrm{~b}$ ), were not included in this study due to the lack of a global estimate for the Mediterranean Sea. Also, recreational catches are not included in national fishery statistics, and only recently a European Union legislation (Council Regulation [EC] No. 1224/2009) has required the survey of recreational fishing activities. Since only few sources of information exist, which have been incorporated into the model, catches may well have been underestimated. Using fisheries statistics supplied to the FAO by individual countries could be another limiting factor. Several studies have indeed confirmed that most of these statistics largely underestimate their likely true catch by a factor of 2 or more (Zeller \& Pauly 2007, Pauly et al. 2014). This could be particularly true for the Southern Mediterranean, where mechanisms to collect fisheries data are less available (FAO 2010) and for some Mediterranean countries where this factor is even higher (Pauly et al. 2014). An unrealistic scenario is also observed regarding mid-water trawling in the Eastern Mediterranean Sea, where this gear shows an impact on marine resources, despite the fact that it does not operate in most of the Eastern Mediterranean countries (Sacchi 2011). Obviously this is an error in the Sea Around Us project database, which at the time it was accessed was still under development.

These caveats represent the major weaknesses of the Mediterranean fisheries data, and some caution should be taken when interpreting the data. Currently, a database on global fisheries reconstruction from 1950 to 2010, which aims at looking at all types of fisheries removals (from reported and unreported landings to recreational landings and discards) is being constructed, including Mediterranean countries (Le Manach et al. 2011, Ulman et al. 2013, Coll et al. 2014b, Pauly et al. 2014). In the near future, this information on catch reconstructions could be integrated in modelling efforts to reduce the limitations explained above, and to capture better the fishing pressure on current and past Mediterranean marine ecosystems. 


\section{Similarities and differences among European regional seas}

The relative total biomass per $\mathrm{km}^{2}$ and per each individual sea reveals that the Adriatic and Western Mediterranean are the areas with the highest biomass followed by the Ionian and Eastern Mediterranean. This confirms a decrease gradient of richness from west to east, as observed in other studies (Bosc et al. 2004), influenced by changes in environmental parameters (e.g. productivity, temperature and salinity) that define and characterize the Mediterranean Sea. Comparing our results to other European seas illustrates that European regional seas are quite diverse. In particular, the Mediterranean Sea stands alone in relation to the type of flows that drive the system and the cycling indices that suggest higher levels of community stress induced by intensive fishing activities, as previously illustrated (Costello et al. 2010).

In regards to ecosystems development, the Mediterranean Sea appears to be in an early development stage, different from the other systems, probably because the ecosystem has been perturbed continuously over a long period of time. Indeed, when ecosystems develop, biomasses and complexity tend to increase and mature, whereas when they are disturbed, e.g. by fishing, they show the opposite trend and stay 'young' (Odum 1969).

One similarity with the other EU ecosystems is given by the TLs of the catches, which are low in the Mediterranean Sea, in the Black Sea and recently in the Baltic Sea (e.g. herrings and sprats have replaced the collapsed Eastern Baltic cod Gadus morhua in the landings; Tomczak et al. 2012), highlighting the importance of small pelagics in the fisheries activities of these areas. Although differences may have occurred in the way models were constructed (such as the number of functional groups and links), these outcomes are in line with other studies that pointed at differences in physical and biological features (from highly eutrophic with frequent hypoxia events to moderately eutrophic and productive or relatively oligotrophic regions; Coll et al. 2010, Tomczak et al. 2012, Mackinson 2014) as the reasons for these differences in diversity among European regional seas (Barale \& Gade 2008, Narayanaswamy et al. 2013).

\section{Concluding remarks}

Overall, our study is the first to provide a basis for understanding and quantifying the structure and functioning of the whole Mediterranean Sea ecosys- tem, including main marine organisms, from low to high TLs, and considering fishing activity. This is also the first Ecopath model that tries to integrate subregions within a unified model to take into consideration differences in biological and environmental characteristics. The construction of 2 food web models (for the past and for current years) enabled us to assess changes in the food web and impacts (in this case fishing) affecting the system. However, further developments of spatial and temporal hind- and forecast analysis are necessary to further model the dynamics of the ecosystem (such as movements of species within and between areas and large migrations) and evaluate the exploitation status of the Mediterranean Sea and explore different management policies and future scenarios. Temporal simulations to hindcast food web dynamics have been developed in regional areas of the Mediterranean Sea such as the Catalan Sea (Coll et al. 2008), the Adriatic Sea (Coll et al. 2009c) and the Ionian Sea (Piroddi et al. 2010). Quantifying the impact of important threats (e.g. climate change and fishing pressure) on a system that is considered 'under siege' (Coll et al. 2012) becomes critically important for ensuring the sustainability of marine resources and the services they provide to humans, and the conservation of this vulnerable ecosystem. This is a step further for the regional assessment of the Mediterranean Sea ecosystem.

Acknowledgements. M.C. was partially supported by a Marie Curie CIG grant-PCIG10-GA-2011-303534 — to the BIOWEB project and the Spanish Research Program Ramon y Cajal. V.C. acknowledges support from NSERC. We thank the 3 anonymous reviewers for their valuable comments and suggestions on the manuscript. We acknowledge all those colleagues from the Joint Research Centre (JRC) who provided essential technical advice to the development of this work. Special thanks go to F. Somma, C. Liquete and L. Gurney for constructive comments on model construction and the draft manuscript; to S. Libralato and S. Heymans, who kindly advised on model development; to G. Notarbartolo di Sciara, A. Canadas, M. Rosso who provided data and/or important insights on marine mammals functional groups; and to M. Tomczak, E. Akoglu and C. Lynam, who provided European regional seas model-derived indicators.

\section{LITERATURE CITED}

Abdul Malak D, Livingstone SR, Pollard D, Polidoro BA and others (comps) (2011) Overview of the conservation status of the marine fishes of the Mediterranean Sea. IUCN, Gland

Akoglu E, Salihoglu B, Libralato S, Oguz T, Solidoro C (2014) An indicator-based evaluation of Black Sea food web dynamics during 1960-2000. J Mar Syst 134:113-125 
Anagnopoulos N, Papaconstantinou C, Oikonomou A, Fragoudes K and others (1998) Sport fisheries in Eastern Mediterranean (Greece and Italy). Final Report. Project N. EC/96/018, European Commission, Brussels

Anticamara JA, Watson R, Gelchu A, Pauly D (2011) Global fishing effort (1950-2010): trends, gaps, and implications. Fish Res 107:131-136

Bănaru D, Mellon-Duval C, Roos D, Bigot JL and others (2013) Trophic structure in the Gulf of Lions marine ecosystem (north-western Mediterranean Sea) and fishing impacts. J Mar Syst 111-112:45-68

Barale V, Gade M (2008) Remote sensing of the European Seas. Springer, Heidelberg

Bearzi G, Agazzi S, Gonzalvo J, Costa M and others (2008) Overfishing and the disappearance of short-beaked common dolphins from western Greece. Endang Species Res 5:1-12

> Bianchi C, Morri C (2000) Marine biodiversity of the Mediterranean Sea: situation, problems and prospects for future research. Mar Pollut Bull 40:367-376

Bosc E, Bricaud A, Antoine D (2004) Seasonal and interannual variability in algal biomass and primary production in the Mediterranean Sea, as derived from 4 years of SeaWiFS observations. Global Biogeochem Cycles 18: GB1005, doi:10.1029/2003GB002034

Bossart GD (2006) Marine mammals as sentinel species for oceans and human health. Oceanography 19:134-137

Boyd IL, Wanless S, Camphuysen C (2006) Top predators in marine ecosystems: their role in monitoring and management. Cambridge University Press, Cambridge

> Bozzano A, Sardà F (2002) Fishery discard consumption rate and scavenging activity in the northwestern Mediterranean Sea. ICES J Mar Sci 59:15-28

Briand F (ed) (2000) Fishing down the Mediterranean food webs. Proc CIESM Workshop Series 12. Kerkyra, Greece

Cardoso AC, Cochrane S, Doerner H, Ferreira JG and others (2010) Scientific support to the European Commission on the Marine Strategy Framework Directive. Management Group Report. EUR 24336 EN - 2010. European Commission, Brussels

> Casale P, Abbate G, Freggi D, Conte N, Oliverio M, Argano $\mathrm{R}$ (2008) Foraging ecology of loggerhead sea turtles Caretta caretta in the central Mediterranean Sea: evidence for a relaxed life history model. Mar Ecol Prog Ser 372:265-276

> Christensen V (1995) Ecosystem maturity - towards quantification. Ecol Model 77:3-32

Christensen V, Pauly D (1993) Flow characteristics of aquatic ecosystems. ICLARM Conf Proc 26:338-352

> Christensen V, Walters CJ (2004) Ecopath with Ecosim: methods, capabilities and limitations. Ecol Model 172: 109-139

Christensen V, Walters C, Pauly D, Forrest R (2008) Ecopath with Ecosim 6: a user's guide. Fisheries Centre, University of British Columbia, Vancouver, BC

> Christensen V, Walters CJ, Ahrens R, Alder J and others (2009) Database-driven models of the world's Large Marine Ecosystems. Ecol Model 220:1984-1996

Christensen V, Coll M, Piroddi C, Steenbeek J, Buszowski J, Pauly D (2014) A century of fish biomass decline in the ocean. Mar Ecol Prog Ser 512:155-166

Cisneros-Montemayor AM, Sumaila UR (2010) A global estimate of benefits from ecosystem-based marine recreation: potential impacts and implications for management. J Bioeconomics 12:245-268
Coll M, Libralato S (2012) Contributions of food web modelling to the ecosystem approach to marine resource management in the Mediterranean Sea. Fish Fish 13:60-88

> Coll M, Palomera I, Tudela S, Sardà F (2006) Trophic flows, ecosystem structure and fishing impacts in the South Catalan Sea, Northwestern Mediterranean. J Mar Syst 59:63-96

Coll M, Santojanni A, Palomera I, Tudela S, Arneri E (2007) An ecological model of the Northern and Central Adriatic Sea: analysis of ecosystem structure and fishing impacts. J Mar Syst 67:119-154

Coll M, Palomera I, Tudela S, Dowd M (2008) Food-web dynamics in the South Catalan Sea ecosystem (NW Mediterranean) for 1978-2003. Ecol Model 217:95-116

Coll M, Bundy A, Shannon LJ (2009a) Ecosystem modelling using the Ecopath with Ecosim approach. In: Megrey BA, Moksness E (eds) Computers in fisheries research, 2nd edn. Springer, New York, NY, p 225-291

Coll M, Palomera I, Tudela S (2009b) Decadal changes in a NW Mediterranean Sea food web in relation to fishing exploitation. Ecol Model 220:2088-2102

Coll M, Santojanni A, Palomera I, Arneri E (2009c) Foodweb changes in the Adriatic Sea over the last three decades. Mar Ecol Prog Ser 381:17-37

Coll M, Piroddi C, Steenbeek J, Kaschner K and others (2010) The biodiversity of the Mediterranean Sea: estimates, patterns, and threats. PLoS ONE 5:e11842

Coll M, Piroddi C, Albouy C, Ben Rais Lasram F and others (2012) The Mediterranean Sea under siege: spatial overlap between marine biodiversity, cumulative threats and marine reserves. Glob Ecol Biogeogr 21:465-480

Coll M, Navarro J, Olson RJ, Christensen V (2013) Assessing the trophic position and ecological role of squids in marine ecosystems by means of food-web models. Deep-Sea Res II 95:21-36

Coll M, Carreras M, Ciércoles C, Cornax MJ, Gorelli G, Morote E, Sáez R (2014a) Assessing fishing and marine biodiversity changes using fishers' perceptions: the Spanish Mediterranean and Gulf of Cadiz case study. PLoS ONE 9:e85670

Coll M, Carreras M, Cornax MJ, Massuti E and others (2014b) Closer to reality: reconstructing total removals in mixed fisheries from Southern Europe. Fish Res 154:179-194

Colloca F, Cardinale M, Maynou F, Giannoulaki M and others (2013) Rebuilding Mediterranean fisheries: a new paradigm for ecological sustainability. Fish Fish 14:89-109

- Costello MJ, Coll M, Danovaro R, Halpin P, Ojaveer H, Miloslavich P (2010) A census of marine biodiversity knowledge, resources, and future challenges. PLoS ONE 5:e12110

> Cury P, Bakun A, Crawford RJ, Jarre A, Quiñones RA, Shannon LJ, Verheye HM (2000) Small pelagics in upwelling systems: patterns of interaction and structural changes in 'wasp-waist' ecosystems. ICES J Mar Sci 57:603-618

Cury P, Shannon L, Shin YJ (2003) The functioning of marine ecosystems: a fisheries perspective. Reykjavik Conference on Responsible Fisheries in the Marine Ecosystem, Reykjavik 1-4 October 2001, p 103-123

EC (European Commission) (2011) Impact assessment of discard reducing policies. EU Discard Annex. Studies in the field of the Common Fisheries Policy and Maritime Affairs. Impact Assessment Studies related to the CFP. Project ZF0926_S10. European Commission, Brussels

FAO (Food and Agriculture Organization of the United Nations) (2010) The state of world fisheries and aquacul- 
ture (SOFIA). Fisheries and Aquaculture Department, FAO, Rome

Ferretti F, Myers RA, Serena F, Lotze HK (2008) Loss of large predatory sharks from the Mediterranean Sea. Conserv Biol 22:952-964

Finn JT (1976) Measures of ecosystem structure and function derived from analysis of flows. J Theor Biol 56: 363-380

Froese R, Pauly D (2010) FishBase. International Center for Living Aquatic Resources Management. www.fishbase.org

Fulton EA (2010) Approaches to end-to-end ecosystem models. J Mar Sys 81:171-183

Gómez de Segura AG, Tomas J, Pedraza S, Crespo E, Raga J (2003) Preliminary patterns of distribution and abundance of loggerhead sea turtles, Caretta caretta, around Columbretes Islands Marine Reserve, Spanish Mediterranean. Mar Biol 143:817-823

Gordoa A, Borrego J, Caillart B, De La Serna J and others (2004) Sport fishing: an informative and economic alternative for tuna fishing in the Mediterranean (SFITUM). EC Project 02/C132/11/41. Final Report, Dec 2004, Vol II. European Commission, Brussels

Hattab T, Ben Rais Lasram F, Albouy C, Romdhane MS and others (2013) An ecosystem model of an exploited southern Mediterranean shelf region (Gulf of Gabes, Tunisia) and a comparison with other Mediterranean ecosystem model properties. J Mar Syst 128:159-174

- Heithaus MR, Frid A, Wirsing AJ, Worm B (2008) Predicting ecological consequences of marine top predator declines. Trends Ecol Evol 23:202-210

Heymans JJ, Coll M, Libralato S, Christensen V (2012) Ecopath theory, modeling, and application to coastal ecosystems. In: McClusky D, Wolanski E (eds) Treatise on estuarine and coastal science, Vol 9. Elsevier, Amsterdam, p 93-111

Heymans JJ, Coll M, Libralato S, Morissette L, Christensen V (2014) Global patterns in ecological indicators of marine food webs: a modelling approach. PloS one 9:e95845

Johnson WM, Lavigne DM (1998) The Mediterranean monk seal. Conservation guidelines: multilingual edition. IMMA Inc., Guelph, ON. Available at http://www.monachusguardian.org/library/guide.pdf

Krom M, Kress N, Brenner S, Gordon L (1991) Phosphorus limitation of primary productivity in the eastern Mediterranean Sea. Limnol Oceanogr 36:424-432

Le Manach F, Dura D, Pere A, Riutorte JJ and others (2011) Preliminary estimate of total marine fisheries catches in Corsica. Fisheries Centre Research Reports Vol 19. Fisheries Centre, University of British Columbia, Vancouver, $\mathrm{BC}$

- Libralato S, Christensen V, Pauly D (2006) A method for identifying keystone species in food web models. Ecol Model 195:153-171

Lindeman RL (1942) The trophic-dynamic aspect of ecology. Ecology 23:399-417

$>$ Lleonart J, Maynou F (2003) Fish stock assessments in the Mediterranean: state of the art. Sci Mar 67:37-49

> Lotze HK, Coll M, Dunne JA (2011) Historical changes in marine resources, food-web structure and ecosystem functioning in the Adriatic Sea, Mediterranean. Ecosystems 14:198-222

Macias D, Garcia-Gorriz E, Piroddi C, Stips A (2014) Biogeochemical control of marine productivity in the Mediterranean Sea during the last 50 years. Global Biogeochem Cycles 28:897-907
Mackinson S (2014) Combined analyses reveal environmentally driven changes in the North Sea ecosystem and raise questions regarding what makes an ecosystem model's performance credible? Can J Fish Aquat Sci 71: $31-46$

Maynou F, Sbrana M, Sartor P, Maravelias C and others (2011) Estimating trends of population decline in longlived marine species in the Mediterranean Sea based on fishers' perceptions. PLoS ONE 6:e21818

Megalofonou P (2005) Incidental catch and estimated discards of pelagic sharks from the swordfish and tuna fisheries in the Mediterranean Sea. Fish Bull 103:620-634

- Micheli F, Halpern BS, Walbridge S, Ciriaco S and others (2013) Cumulative human impacts on Mediterranean and Black Sea marine ecosystems: assessing current pressures and opportunities. PLoS ONE 8:e79889

> Moloney CL, Jarre A, Arancibia H, Bozec YM, Neira S, Roux JP, Shannon LJ (2005) Comparing the Benguela and Humboldt marine upwelling ecosystems with indicators derived from inter-calibrated models. ICES J Mar Sci 62: 493-502

> Monaco ME, Ulanowicz RE (1997) Comparative ecosystem trophic structure of three US mid-Atlantic estuaries. Mar Ecol Prog Ser 161:239-254

Morissette L (2007) Complexity, cost and quality of ecosystem models and their impact on resilience: a comparative analysis, with emphasis on marine mammals and the Gulf of St. Lawrence. PhD thesis, University of British Columbia, Vancouver

> Moutopoulos DK, Libralato S, Solidoro C, Stergiou KI (2013) Toward an ecosystem approach to fisheries in the Mediterranean Sea: multi-gear/multi-species implications from an ecosystem model of the Greek Ionian Sea. J Mar Syst 113-114:13-28

> Narayanaswamy BE, Coll M, Danovaro R, Davidson K, Ojaveer H, Renaud PE (2013) Synthesis of knowledge on marine biodiversity in European seas: from census to sustainable management. PLoS ONE 8:e58909

Odum EP (1969) The strategy of ecosystem development. Science 164:262-270

> Oro D, Ruiz X (1997) Exploitation of trawler discards by breeding seabirds in the north-western Mediterranean: differences between the Ebro Delta and the Balearic Islands areas. ICES J Mar Sci 54:695-707

> Papaconstantinou C, Farrugio H (2000) Fisheries in the Mediterranean. Mediterr Mar Sci 1:5-18

Pauly D, Christensen V (1995) Primary production required to sustain global fisheries. Nature 374:255-257

Pauly D, Ulman A, Piroddi C, Bultel E, Coll M (2014) 'Reported' versus 'likely' fisheries catches of four Mediterranean countries. Sci Mar 78:11-17

Pawson M, Tingley D, Padda G, Glenn H (2007) EU contract FISH/2004/011 on 'sports fisheries' (or marine recreational fisheries) in the EU. Prepare for the European Commission Directorate-General for Fisheries. Final report (March 2007). Cefas, Lowestoft

Pierce GJ, Valavanis VD, Guerra A, Jereb P and others (2008) A review of cephalopod-environment interactions in European Seas. Hydrobiologia 612:49-70

> Pikitch EK, Santora E, Babcock EA, Bakun A and others (2004) Ecosystem-based fishery management. Science 305:346-347

> Pikitch EK, Rountos KJ, Essington TE, Santora C and others (2014) The global contribution of forage fish to marine fisheries and ecosystems. Fish Fish 15:43-64 
Pinardi N, Zavatarelli M, Arneri E, Crise A, Ravaioli M (2006) The physical, sedimentary and ecological structure and variability of shelf areas in the Mediterranean sea $(27, \mathrm{~S})$. In: Robinson AR, Brink KH (eds) The sea, Vol 14. Harvard University Press, Cambridge, MA, p 1243-1330

Piroddi C, Bearzi G, Christensen V (2010) Effects of local fisheries and ocean productivity on the northeastern Ionian Sea ecosystem. Ecol Model 221:1526-1544

Piroddi C, Bearzi G, Gonzalvo J, Christensen V (2011) From common to rare: the case of the Mediterranean common dolphin. Biol Conserv 144:2490-2498

Piroddi C, Gristina M, Zylich K, Ulman A, Zeller D, Pauly D (2014) Reconstruction of Italy's marine fisheries catches (1950-2010). Fisheries Centre Working Paper no. 201422. Fisheries Centre, University of British Columbia, Vancouver, BC. Available at: www.seaaroundus.org/ about/index.php/working-papers/

Power ME, Tilman D, Estes JA, Menge BA and others (1996) Challenges in the quest for keystones. Bioscience 46: 609-620

Puig P, Canals M, Company JB, Martín J and others (2012) Ploughing the deep sea floor. Nature 489:286-289

Reeves R, Notarbartolo di Sciara G (eds) (2006) The status and distribution of cetaceans in the Black Sea and Mediterranean Sea. IUCN Centre for Mediterranean Cooperation, Malaga

Sacchi J (2011) Analysis of economic activities in the Mediterranean: fishery and aquaculture sectors. Plan Bleu UNEP/MAP Regional Activity Centre, Valbonne

Schaefer MB (1954) Some aspects of the dynamics of populations important to the management of the commercial marine fisheries. Inter-Am Trop Tuna Comm Bull 1: 23-56

Sergio F, Caro T, Brown D, Clucas B and others (2008) Top predators as conservation tools: ecological rationale, assumptions, and efficacy. Annu Rev Ecol Evol Syst 39: 1-19

Shin YJ, Shannon L, Cury P (2004) Simulations of fishing effects on the southern Benguela fish community using an individual-based model: learning from a comparison with Ecosim. Afr J Mar Sci 26:95-114

Siokou-Frangou I, Christaki U, Mazzocchi M, Montresor M, Ribera d'Alcalá M, Vaqué D, Zingone A (2010) Plankton in the open Mediterranean Sea: a review. Biogeosciences 7:1543-1586

Sournia A (1973) La production primaire planctonique en Méditerranée; essai de mise à jour. Cooperative Investigations in the Mediterranean, International Coordinator and Operational Unit; Étude en commun de la Méditerranée, Coordonnateur international et Unité opérationnelle, Monte Carlo

Tecchio S, Coll M, Christensen V, Company JB, RamírezLlodra E, Sardà F (2013) Food web structure and vulnerability of a deep-sea ecosystem in the NW Mediterranean Sea. Deep-Sea Res I 75:1-15

Tomas J, Aznar F, Raga J (2001) Feeding ecology of the loggerhead turtle Caretta caretta in the western Mediterranean. J Zool 255:525-532

Tomczak M, Niiranen S, Hjerne O, Blenckner T (2012) Ecosystem flow dynamics in the Baltic Proper-using a multi-trophic dataset as a basis for food-web modelling. Ecol Model 230:123-147

Editorial responsibility: Konstantinos Stergiou, Thessaloniki, Greece
Tomczak MT, Heymans JJ, Yletyinen J, Niiranen S, Otto SA, Blenckner T (2013) Ecological network indicators of ecosystem status and change in the Baltic Sea. PLoS ONE 8: e75439

> Torres MÁ, Coll M, Heymans JJ, Christensen V, Sobrino I (2013) Food-web structure of and fishing impacts on the Gulf of Cadiz ecosystem (South-western Spain). Ecol Model 265:26-44

Trites A, Christensen V, Pauly D (2006) Effects of fisheries on ecosystems: just another top predator? In: Boyd IL, Wanless S, Camphuysen CJ (eds) Top predators in marine ecosystems. Cambridge University Press, Cambridge, p 11-27

Tsagarakis K, Coll M, Giannoulaki M, Somarakis S, Papaconstantinou C, Machias A (2010) Food-web traits of the North Aegean Sea ecosystem (Eastern Mediterranean) and comparison with other Mediterranean ecosystems. Estuar Coast Shelf Sci 88:233-248

Tsagarakis K, Palialexis A, Vassilopoulou V (2013) Mediterranean fishery discards: review of the existing knowledge. ICES J Mar 71:1219-1234

Tsikliras A, Stergiou K, Moutopoulos D (2007) Reconstruction of Greek marine fisheries landings: national versus FAO statistics. In: Zeller D, Pauly D (eds) Reconstruction of marine fisheries catches for key countries and regions (1950-2005). Fisheries Centre Research Reports 15. Fisheries Centre, University of British Columbia, Vancouver, BC, p 121-137

Tsikliras A, Tsiros VZ, Stergiou K (2013a) Assessing the state of Greek marine fisheries resources. Fish Manag Ecol 20: 34-41

Tsikliras AC, Dinouli A, Tsalkou E (2013b) Exploitation trends of the Mediterranean and Black Sea fisheries. Acta Adriat 54:273-282

Ulanowicz RE (1986) Growth and development: ecosystems phenomenology. Springer-Verlag, New York, NY

Ulanowicz R (1995) Ecosystem trophic foundations: Lindeman exonerata. In: Patten BC, Jørgensen SE (eds) Complex ecology: the part-whole relation in ecosystems. Prentice-Hall, Englewood Cliffs, NJ, p 549-560

Ulman A, Bekisoglu S, Zengin M, Knudsen S and others (2013) From bonito to anchovy: a reconstruction of Turkey's marine fisheries catches (1950-2010). Mediterr Mar Sci 14:309-342

UNEP/MAP (United Nations Environment Programme/ Mediterranean Action Plan) (1994) Report of the Meeting of Experts on the Evaluation of the Implementation of the Action Plan for the Management of the Mediterranean Monk Seal. UNEP(OCA)/MED WG.87/4. UNEP, Tunis

- Vasilakopoulos P, Maravelias CD, Tserpes G (2014) The alarming decline of Mediterranean fish stocks. Curr Biol 24:1643-1648

Vassilopoulou V (2012) Review of existing knowledge on fisheries by-catches and discards in the GFCM area. SAC14/2012/Dma.6. General Fisheries Commission for the Mediterranean, Sofia

Walters CJ, Hilborn R, Christensen V (2008) Surplus production dynamics in declining and recovering fish populations. Can J Fish Aquat Sci 65:2536-2551

Zeller D, Pauly D (eds) (2007) Reconstruction of marine fisheries catches for key countries and regions (1950-2005). Fisheries Centre Research Reports 15. Fisheries Centre, University of British Columbia, Vancouver, BC

Submitted: December 5, 2014; Accepted: June 6, 2015

Proofs received from author(s): July 27, 2015 